\title{
Form Factors for Branched Polymers with Excluded Volume
}

\author{
Boualem Hammouda \\ National Institute of Standards and Technology, \\ Gaithersburg, MD 20899 \\ hammouda@nist.gov
}

The form factors for star-branched polymers with linear branches or with looping branches are calculated. The effect of chain swelling excluded volume is incorporated through an excluded volume parameter approach. The form factor for ring polymers is also included, since it is nicely derived as a special case. Furthermore, the form factor for dendrimers with excluded volume is also calculated. In order to evaluate the form factor for stars with looping branches, the multivariate Gaussian function is used to close the looping branches. Analytical results are possible in the Gaussian chain case (i.e., with no excluded volume), but the calculations are left in a form involving summations over monomers when the general case incorporates excluded volume.

Key words: dendrimers; excluded volume effect; looping branches; polymer ring; small-angle scattering form factors; star-branched polymers.

Accepted: March 25, 2016

Published: April 13, 2016

http://dx.doi.org/10.6028/jres.121.006

\section{Introduction}

Scattering is a measurement technique of choice for polymer systems. In order to understand scattering data, a model representing the structure is needed. The single macromolecule form factor is an essential ingredient for calculating the scattering function. The form factors for a few branched polymer systems are discussed here. These include star-branched polymers with linear branches or with looping arms and dendrimers. The effect of excluded volume is incorporated using an approach based on the excluded volume parameter. This approach is familiar for linear polymer chains and is generalized here to branched polymers.

Scattering methods have been applied to great many branched polymer systems. This motivated an effort at modeling the scattering factors of regularly branched polymers like star-branched polymers or dendrimers. A few references are included here.

Benoit started the modeling effort by calculating the form factor for Gaussian stars [1]. A recent model used the two-point correlation function to derive the form factor for star-branched polymers [2]. The twopoint correlation function that was used was obtained from Monte Carlo simulations [3, 4] for linear chains that agreed with renormalization group calculations [5]. This approach incorporated excluded volume due to chain swelling. The second form of excluded volume which is due to solid angle exclusion of one arm excluding other arms close to the star center is difficult to account for.

Renormalization group approaches are well suited for calculations with self-avoiding chain swelling in linear polymers [6]. The renormalization group approach was applied to star-branched polymers to account for chain swelling [7]. A closed form expression for the scattering factor was presented after the tedious task of evaluating some 21 integrals that contribute to the various diagrammatic representations of the excluded volume interactions. This paper presented an empirical form for the form factor in specific cases using a small-angle (low-Q) expansion. 
The Benoit model [1] calculates the form factor for Gaussian chain stars. This model was extensively used to analyze scattering data from star-branched polymers such as for instance in theta solvent [8] or in melts [9]. This model, however, does not incorporate excluded volume and is not appropriate for the analysis of scattering data from swollen chains $[10,11]$.

The form factor for star-branched polymers with looping branches is calculated in this paper. Such form factor was not found in the open literature even in the Gaussian chain case. Its form is derived here for swollen chains. This form reproduces the single-branch case of cyclic (ring) polymer.

Finally the form factor for dendrimers is calculated that incorporates chain swelling.

\section{Star-Branched Polymer with Excluded Volume}

The Benoit approach [1] is used here to calculate the scattering form factor for a flexible star-branched polymer represented in Fig. 1. The excluded volume approach developed for linear Gaussian chains [12, 13 ] is generalized for star-branched polymers.

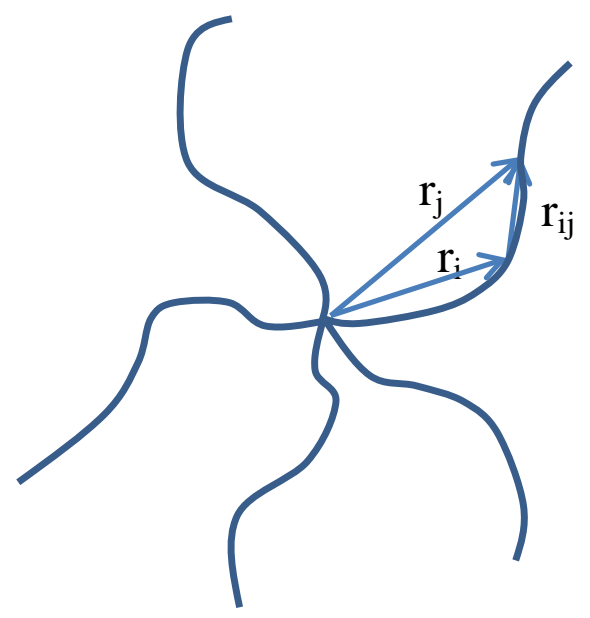

Fig. 1. Schematic representation of the star polymer. $\vec{r}_{i j}=\vec{r}_{i}-\vec{r}_{j}$ is the interdistance between monomers $i$ and $j$ on the same branch.

\subsection{Form Factor Amplitude for a Single-Branch}

Consider monomer i on a branch of the star referenced with respect to the central monomer (branching point) referred to as monomer 1 . Each branch contains $n$ monomers. The form factor amplitude for one branch is given by a single summation over $\mathrm{i}$ :

$$
\mathrm{F}(\mathrm{Q})=\frac{1}{\mathrm{n}} \sum_{\mathrm{i}=1}^{\mathrm{n}}\left\langle\exp \left(-\mathrm{iQ} \cdot \overrightarrow{\mathrm{r}}_{\mathrm{ii}}\right)\right\rangle
$$

The average is taken over conformations:

$$
\left\langle\exp \left(-\mathrm{i} \overrightarrow{\mathrm{Q}} \cdot \overrightarrow{\mathrm{r}}_{\mathrm{ii}}\right)\right\rangle=\int \mathrm{d}^{3} \mathrm{r}_{\mathrm{ij}} \mathrm{P}\left(\overrightarrow{\mathrm{r}}_{\mathrm{ij}}\right) \exp \left(-\mathrm{i} \overrightarrow{\mathrm{Q}} \cdot \overrightarrow{\mathrm{r}}_{\mathrm{ii}}\right)
$$

For a flexible polymer coil obeying Gaussian statistics: 


$$
\mathrm{P}\left(\overrightarrow{\mathrm{r}}_{\mathrm{j}}\right)=\left(\frac{3}{2 \pi<\mathrm{r}_{1 j}{ }^{2}>}\right)^{3 / 2} \exp \left[-\frac{3 \mathrm{r}_{1 \mathrm{j}}{ }^{2}}{2<\mathrm{r}_{1 j}{ }^{2}>}\right] \text {. }
$$

A model describing polymer chain conformations with excluded volume is used. The average of the segment interdistances squared is kept in the general form:

$$
<\mathrm{r}_{1 \mathrm{j}}^{2}>=\mathrm{a}^{2}|1-\mathrm{j}|^{2 \mathrm{v}} .
$$

$v$ is the excluded volume parameter.

$$
\mathrm{F}(\mathrm{Q})=\frac{1}{\mathrm{n}} \sum_{\mathrm{i}=1}^{\mathrm{n}} \exp \left[-\frac{\mathrm{Q}^{2} \mathrm{a}^{2}|1-\mathrm{i}|^{2 v}}{6}\right]
$$

Changing variables $j=i-1, x=j / n$ then going to the continuous limit, one obtains:

$$
F(Q)=\int_{0}^{1} d x \exp \left[-\frac{Q^{2} a^{2} n^{2 v}}{6} x^{2 v}\right]
$$

Here $a$ is the polymer chain statistical segment length, $n$ is the degree of polymerization of each branch and $\mathrm{x}$ is the integration variable. The variable change $\mathrm{t}=\mathrm{Ux}^{2 v}$ is performed. After a few manipulations, $\mathrm{F}(\mathrm{Q})$ can be expressed in terms of the incomplete gamma function:

$$
\gamma(\mathrm{d}, \mathrm{U})=\int_{0}^{\mathrm{U}} \mathrm{dt} \exp (-\mathrm{t}) \mathrm{t}^{\mathrm{d}-1}
$$

as follows:

$$
\mathrm{F}(\mathrm{Q})=\frac{1}{2 v \mathrm{U}^{1 / 2 v}} \gamma(1 / 2 v, \mathrm{U})
$$

The variable $\mathrm{U}$ is given in terms of the scattering variable $\mathrm{Q}$ as:

$$
\mathrm{U}=\frac{\mathrm{Q}^{2} \mathrm{a}^{2} \mathrm{n}^{2 v}}{6}=\frac{\mathrm{Q}^{2} \mathrm{R}_{\mathrm{g}}{ }^{2}(2 v+1)(2 v+2)}{6} \text {. }
$$

The radius of gyration squared has been defined as:

$$
\mathrm{R}_{\mathrm{g}}{ }^{2}=\frac{\mathrm{a}^{2} \mathrm{n}^{2 v}}{(2 v+1)(2 v+2)}
$$

When $v=0.5$, the form factor amplitude reduces to:

$$
F(Q)=\left(\frac{1-\exp \left(-\mathrm{Q}^{2} \mathrm{R}_{\mathrm{g}}{ }^{2}\right)}{\mathrm{Q}^{2} \mathrm{R}_{\mathrm{g}}{ }^{2}}\right)
$$

Where $\mathrm{R}_{\mathrm{g}}$ is the radius of gyration (with $\mathrm{R}_{\mathrm{g}}{ }^{2}=\mathrm{na}^{2} / 6$ for $v=0.5$ ). 


\subsection{Form Factor for a Single-Branch}

In order to calculate the form factor for a single-branch, consider two monomers i and $\mathrm{j}$.

$$
P(Q)=\frac{1}{n^{2}} \sum_{i=1}^{n} \sum_{j=1}^{n}\left\langle\exp \left(-i \vec{Q} \cdot \vec{r}_{i j}\right)\right\rangle .
$$

In the continuous limit, the double summation is changed into integration. After a few manipulations, one obtains the following result [14]:

$$
P(Q)=2 \int_{0}^{1} d x(1-x) \exp \left[-\frac{Q^{2} a^{2}}{6} n^{2 v} x^{2 v}\right]
$$

This integral was performed [13] to yield:

$$
\mathrm{P}(\mathrm{Q})=\frac{1}{v \mathrm{U}^{1 / 2 v}} \gamma\left(\frac{1}{2 v}, \mathrm{U}\right)-\frac{1}{v \mathrm{U}^{1 / v}} \gamma\left(\frac{1}{v}, \mathrm{U}\right)
$$

Here, $\gamma(\mathrm{x}, \mathrm{U})$ is the incomplete gamma function and $\mathrm{U}$ has been defined before.

Note that for fully swollen chains $v=3 / 5$ (good solvent), for Gaussian chains $v=1 / 2$ (theta solvent) while for collapsed chains $v=1 / 3$ (bad solvent).

\subsection{Form Factor for Star-Branched Polymer}

In the case of star-branched polymers, the star form factor is given for a star with $\mathrm{n}_{\mathrm{b}}$ branches by:

$$
\mathrm{P}_{\mathrm{star}}(\mathrm{Q})=\frac{1}{\mathrm{n}_{\mathrm{b}}{ }^{2}}\left[\mathrm{n}_{\mathrm{b}} \mathrm{P}_{\mathrm{sb}}(\mathrm{Q})+\mathrm{n}_{\mathrm{b}}\left(\mathrm{n}_{\mathrm{b}}-1\right) \mathrm{P}_{\mathrm{ib}}(\mathrm{Q})\right]
$$

in terms of the single-branch form factor $\mathrm{P}_{\mathrm{sb}}(\mathrm{Q})$ and the inter-branch form factor $\mathrm{P}_{\mathrm{ib}}(\mathrm{Q})$. For Gaussian chains (i.e., when $v=0.5$ ), $\mathrm{P}_{\mathrm{ib}}(\mathrm{Q})$ can be expressed as $\mathrm{P}_{\mathrm{ib}}(\mathrm{Q})=|\mathrm{F}(\mathrm{Q})|^{2}$ in term of the form factor amplitude $\mathrm{F}(\mathrm{Q})$.

When excluded volume contributes (i.e., when $v \neq 0.5$ ), the form $\mathrm{P}_{\mathrm{ib}}(\mathrm{Q})=|\mathrm{F}(\mathrm{Q})|^{2}$ is approximate and is referred to as $\mathrm{P}_{\mathrm{ib}}^{(1)}(\mathrm{Q})$ in order to distinguish it for the formally "exact” form (within the context of the present formalism) $\mathrm{P}_{\mathrm{ib}}^{(2)}(\mathrm{Q})$ which is expressed as follows:

$$
P_{i b}^{(2)}(Q)=\frac{(2 n)^{2} P_{s b}(Q, 2 n)-2 n^{2} P_{s b}(Q, n)}{2 n^{2}}
$$

This is in analogy to the cross product in the binomial formula. For instance, for two branches containing $\mathrm{n}_{1}$ and $n_{2}$ monomers, the cross product would be expressed as $n_{1} n_{2}=\left(\left(n_{1}+n_{2}\right)^{2}-n_{1}^{2}-n_{2}{ }^{2}\right) / 2$. Here $P_{s b}(Q, n)$ is the form factor for a single-branch with $n$ monomers and $\mathrm{P}_{\mathrm{sb}}(\mathrm{Q}, 2 \mathrm{n})$ is that for a chain formed with two branches (containing $2 \mathrm{n}$ monomers). The form factor with excluded volume has been calculated in the previous section. 


\subsection{Trends of the Form Factors}

To take advantage of this formalism, a few figures are plotted. First, the single-branch form factor $\mathrm{P}_{\mathrm{sb}}(\mathrm{Q})$ and inter-branch form factor $\mathrm{P}_{\mathrm{ib}}(\mathrm{Q})$ are plotted without $(v=0.5)$ excluded volume. The star-branched polymer form factor $\mathrm{P}_{\text {star }}(\mathrm{Q})$ is plotted as well. These plots were produced for the following parameters $\mathrm{a}=$ $5 \AA, n=100$, and $n_{B}=3$. The overall form factor $P_{\text {star }}(Q)$ follows the inter-branch part $P_{i b}(Q)$ at low-Q but scales with the single-branch part $\mathrm{P}_{\mathrm{sb}}(\mathrm{Q})$ at high-Q as shown in Fig. 2. For $v=0.5$, $\mathrm{P}_{\mathrm{sb}}(\mathrm{Q} \rightarrow \infty) \sim 1 / \mathrm{Q}^{1 / v} \sim 1 / \mathrm{Q}^{2}$ while $\mathrm{P}_{\mathrm{ib}}^{(1)}(\mathrm{Q} \rightarrow \infty) \sim|\mathrm{F}(\mathrm{Q} \rightarrow \infty)|^{2} \sim\left|1 / \mathrm{Q}^{1 / v}\right|^{2} \sim 1 / \mathrm{Q}^{4}$

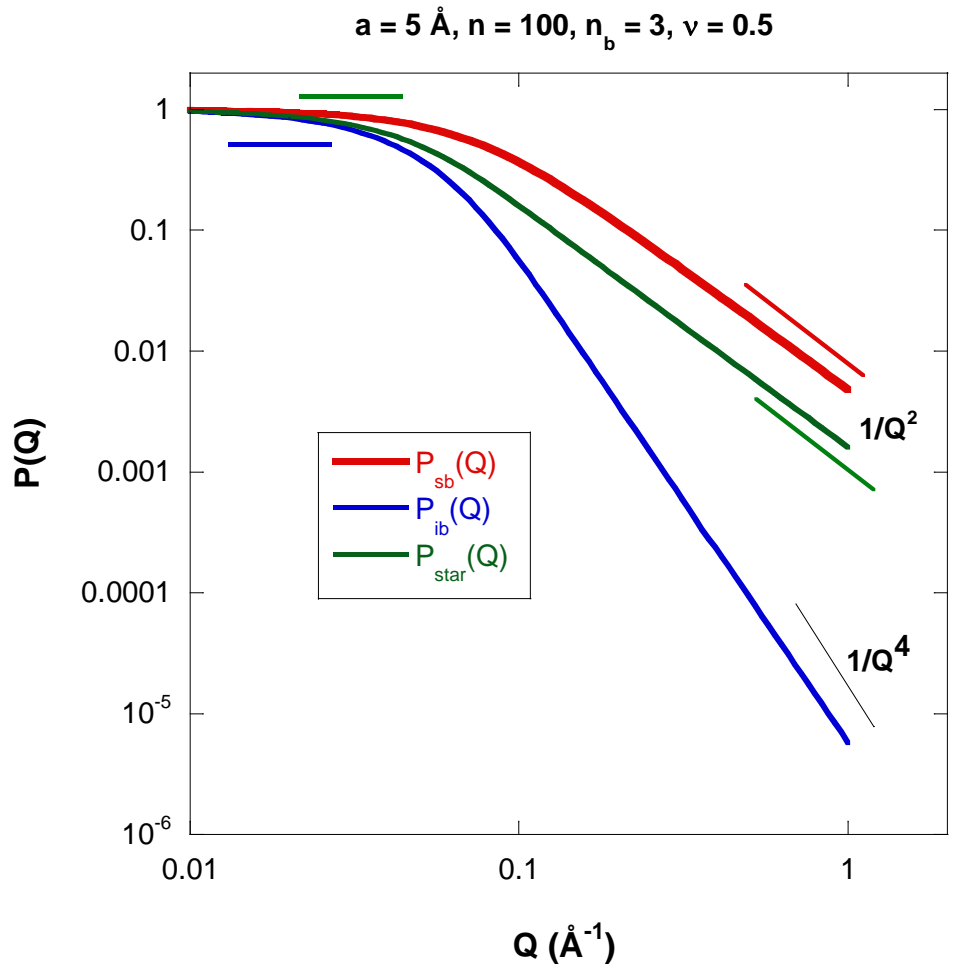

Fig. 2. Single-branch $\mathrm{P}_{\mathrm{sb}}(\mathrm{Q})$, inter-branch $\mathrm{P}_{\mathrm{ib}}(\mathrm{Q})$ and complete $\mathrm{P}_{\text {star }}(\mathrm{Q})$ form factors for a star-branched polymer with a $=5 \AA$, $n=100$, $\mathrm{n}_{\mathrm{b}}=3$, and $v=0.5$.

The Kratky plot $\left(\mathrm{Q}^{2} \mathrm{P}(\mathrm{Q})\right.$ vs $\left.\mathrm{Q}\right)$ is often used for branched polymers since it is characterized by a peak at intermediate-Q. In this case, Kratky plots show that the high-Q asymptotic limit for the single-branch form factor is $\mathrm{Q}^{2} \mathrm{P}_{\mathrm{sb}}(\mathrm{Q} \rightarrow \infty) \sim \mathrm{Q}^{2-1 / v} \sim 1 / \mathrm{Q}^{0}$ for $v=0.5$ as shown in Fig. 3. The inter-branch form factor is characterized by a peak in the Kratky plots since the cross term changes trend to the form $\mathrm{Q}^{2} \mathrm{P}_{\mathrm{ib}}(\mathrm{Q} \rightarrow \infty) \sim \mathrm{Q}^{2-2 / v} \sim 1 / \mathrm{Q}^{2}$ for $v=0.5$. Kratky plots have been presented in a log-log plot in order to emphasize the scaling trends.

Figure 4 compares the form factors for star-branched polymers with the two forms for the inter-branch form factors $\mathrm{P}_{\mathrm{ib}}^{(1)}(\mathrm{Q})$ and $\mathrm{P}_{\mathrm{ib}}^{(2)}(\mathrm{Q})$ with full excluded volume $v=0.6$. These are compared to the Gaussian chain case (i.e., with no excluded volume $v=0.5)$. Note that in that case $(v=0.5)$ the two form factors are identical while in the non-Gaussian chain case, they are slightly different. 


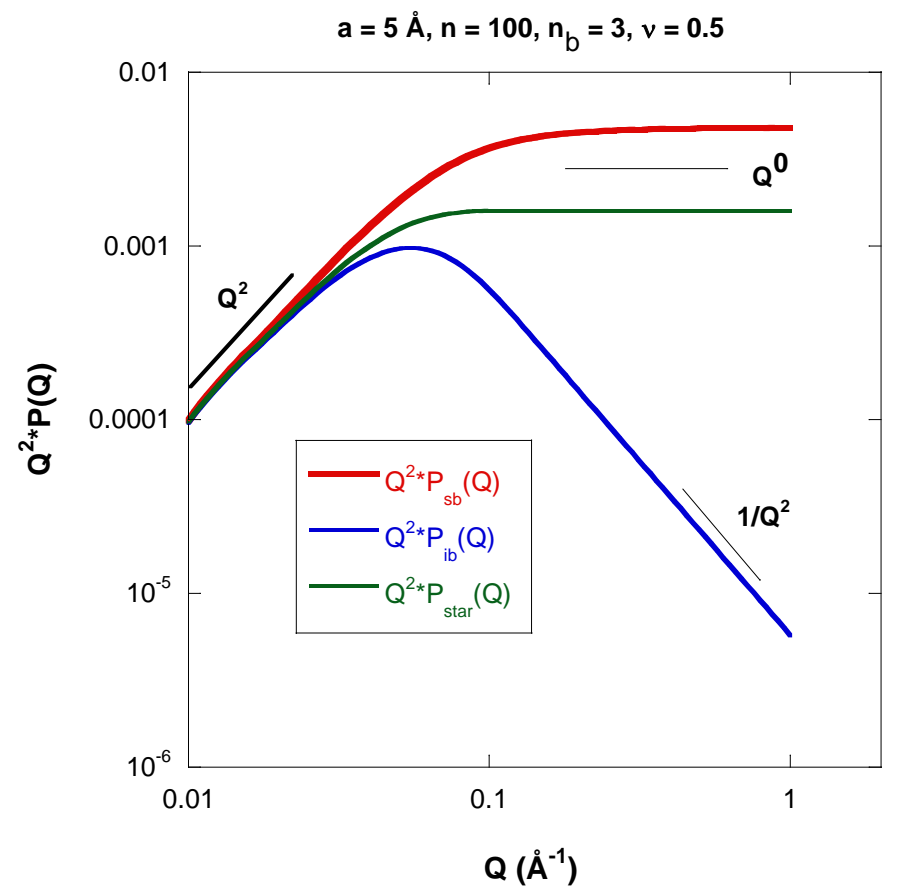

Fig. 3. Kratky plot for the single-branch $\mathrm{P}_{\mathrm{sb}}(\mathrm{Q})$, inter-branch $\mathrm{P}_{\mathrm{ib}}(\mathrm{Q})$ and complete $\mathrm{P}_{\mathrm{star}}(\mathrm{Q})$ form factors for a star-branched polymer with $\mathrm{a}=5 \AA, \mathrm{n}=100, \mathrm{n}_{\mathrm{b}}=3$, and $v=0.5$.

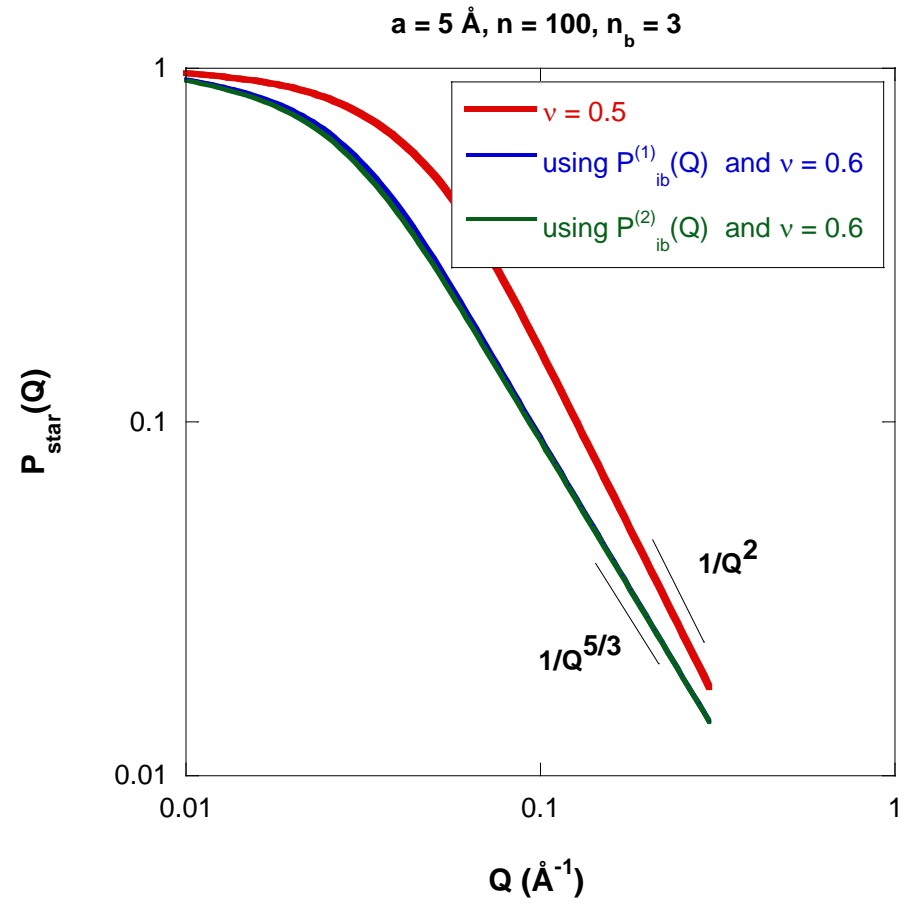

Fig. 4. Form factor $P_{\text {star }}(Q)$ for a star-branched polymer with $a=5 \AA, n=100, n_{b}=3$. The first curve uses the form factor amplitude $\mathrm{F}(\mathrm{Q})$ method and $v=0.5$. The second method uses the same method but for $v=0.6$ and the third curve uses the block copolymer method (binomial formula) and $v=0.6$. Results for these last two methods are so close that the two curves overlap. 
The Kratky plots for the same conditions are plotted in Fig. 5.

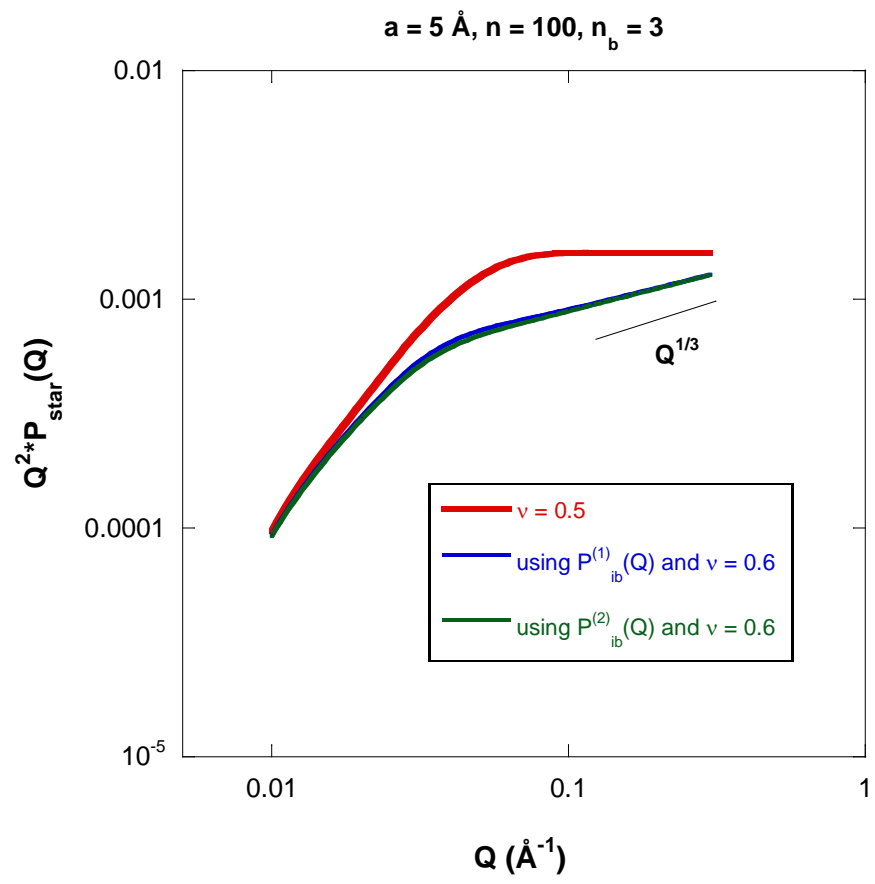

Fig. 5. Kratky plot for the same conditions as the previous figure.

Next, the number of branches $n_{b}$ is varied for the case with fully swollen chains $(v=0.6)$ in Fig. 6 . Branching becomes pronounced for $n_{b}>3$ as evidenced by the peak in the Kratky plot.

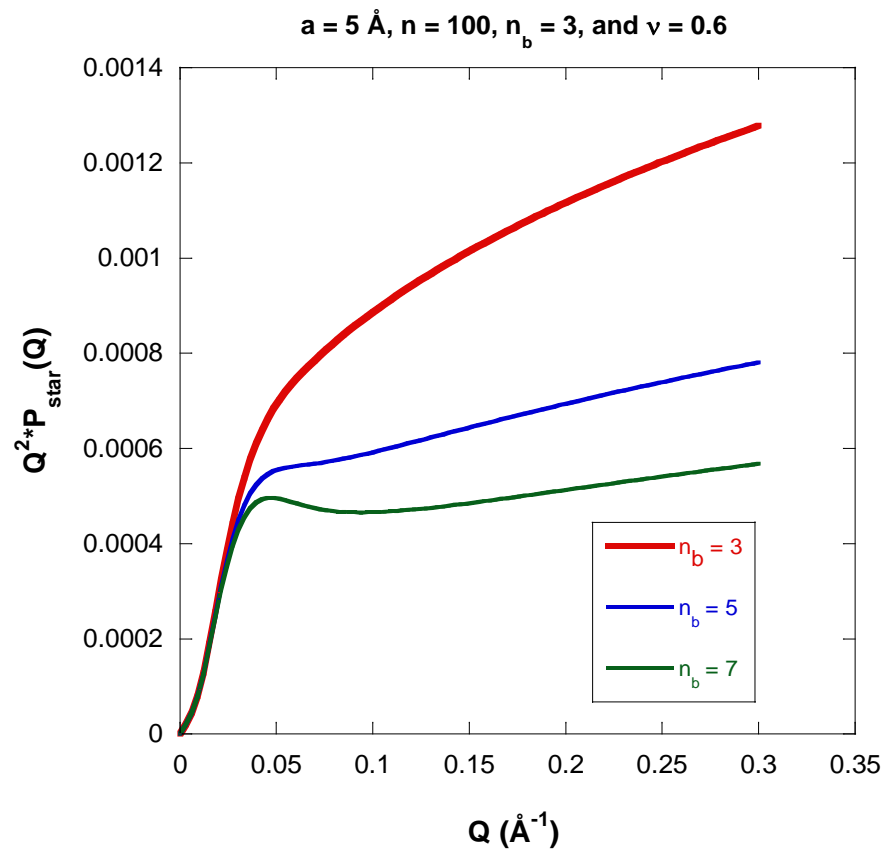

Fig. 6. Kratky plot for a star-branched polymer with $\mathrm{a}=5 \AA, \mathrm{n}=100, \mathrm{n}_{\mathrm{b}}=3$, and $v=0.6$. The number of branches is varied. As the number of branches increases, the Kratky plot peak becomes more prominent. 


\section{Form Factor for Star Polymers with Looping Branches}

The form factor for star-branched polymers with looping branches is derived here. The simple case of a flexible polymer ring is considered first.

\subsection{Polymer Ring}

The form factor for a polymer ring can be calculated using a multivariate Gaussian distribution approach $[15,16]$. For a Gaussian polymer ring, $\mathrm{P}(\mathrm{Q})$ can be calculated as follows:

$$
P(Q)=\frac{1}{n^{2}} \sum_{i, j}^{n} \exp \left[-\frac{Q^{2}<r_{i j}^{2}>}{6}\right]
$$

In order to evaluate $\left\langle\mathrm{r}_{\mathrm{ij}}{ }^{2}>\right.$, construct the ring from a linear chain, which is then closed (see Fig. 7).

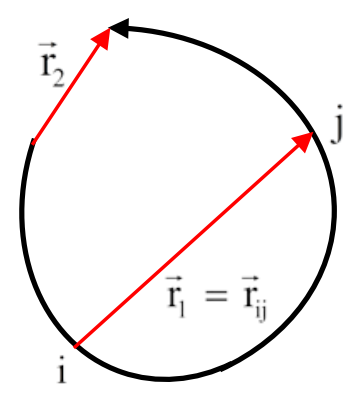

Fig. 7. A polymer ring can be constructed by closing a linear chain.

A bivariate Gaussian distribution is defined as:

$$
\mathrm{P}\left(\overrightarrow{\mathrm{r}}_{1}, \overrightarrow{\mathrm{r}}_{2}\right)=\left(\frac{3}{2 \pi \mathrm{a}^{2}}\right)^{3} \frac{1}{\Delta} \exp \left(-\frac{3}{2 \mathrm{a}^{2}} \sum_{\mu, v}^{2} \overrightarrow{\mathrm{r}}_{\mu} \cdot \mathrm{D}_{\mu v} \cdot \overrightarrow{\mathrm{r}}_{v}\right)
$$

Here $\overrightarrow{\mathrm{r}}_{1}=\overrightarrow{\mathrm{r}}_{\mathrm{ij}}, \Delta$ is the determinant of the correlation matrix $\underline{\underline{\mathrm{C}}}, \underline{\underline{\mathrm{D}}}$ is the inverse $\left(\underline{\underline{\mathrm{D}}}=\underline{\underline{C}}^{-1}\right)$ and the 4 elements of $\underline{\underline{C}}$ are given by: $\mathrm{C}_{\mu \nu}=\left\langle\overrightarrow{\mathrm{r}}_{\mu} \cdot \overrightarrow{\mathrm{r}}_{v}>/ \mathrm{a}^{2}\right.$ with $\{\mu, v=1,2\}$. The ring closing step is formed by setting $\overrightarrow{\mathrm{r}}_{2}=0$. This leaves a univariate Gaussian distribution:

$$
\mathrm{P}\left(\overrightarrow{\mathrm{r}}_{1}\right)=\frac{\mathrm{P}\left(\overrightarrow{\mathrm{r}}_{1}, 0\right)}{\int \mathrm{d} \overrightarrow{\mathrm{r}}_{1} \mathrm{P}\left(\overrightarrow{\mathrm{r}}_{1}, 0\right)}=\left(\frac{3}{2 \pi \mathrm{a}^{2}}\right)^{\frac{3}{2}} \mathrm{D}_{11}^{\frac{3}{2}} \exp \left(-\frac{3}{2 \mathrm{a}^{2}} \mathrm{D}_{11} \overrightarrow{\mathrm{r}}_{1}^{2}\right)
$$

The average mean square distance between two monomers $\mathrm{i}$ and $\mathrm{j}$ that belong to the looping block of length $\mathrm{n}$ and statistical segment length a is therefore given by:

$$
\frac{<\mathrm{r}_{\mathrm{ij}}^{2}>}{\mathrm{a}^{2}}=\frac{1}{\mathrm{D}_{11}}
$$

More specifically, in this case: 


$$
\begin{aligned}
& \mathrm{C}_{11}=\frac{<\mathrm{r}_{1}^{2}>}{\mathrm{a}^{2}}=(\mathrm{j}-\mathrm{i}) \\
& \mathrm{C}_{12}=\frac{<\mathrm{r}_{1} \mathrm{r}_{2}>}{\mathrm{a}^{2}}=(\mathrm{j}-\mathrm{i}) \\
& \mathrm{C}_{22}=\frac{<\mathrm{r}_{2}^{2}>}{\mathrm{a}^{2}}=\mathrm{n} .
\end{aligned}
$$

So that:

$$
\begin{aligned}
& D_{11}=\frac{n}{|i-j|(n-|i-j|)} \\
& <r_{i j}^{2}>=\frac{a^{2}}{D_{11}}=a^{2}|i-j|\left(1-\frac{|i-j|}{n}\right) .
\end{aligned}
$$

The form factor for the polymer ring is therefore:

$$
P(Q)=\frac{1}{n^{2}} \sum_{i, j}^{n} \exp \left[-\frac{Q^{2} a^{2}|i-j|}{6}\left(1-\frac{|i-j|}{n}\right)\right]=\frac{1}{n^{2}}\left\{n+2 n \sum_{k=1}^{n}\left(1-\frac{k}{n}\right) \exp \left[-\frac{Q^{2} a^{2} k}{6}\left(1-\frac{k}{n}\right)\right]\right\} \text {. }
$$

The first term is dropped for $\mathrm{n}>>1$. In order to simplify this equation, we take the continuous chain limit (whereby $\mathrm{Q}^{2} \mathrm{a}^{2} / 6<<1$ and $\mathrm{n}>>1$ but keeping $\mathrm{Q}^{2} \mathrm{a}^{2} \mathrm{n} / 6$ finite) and change the summations into integrations:

$$
P(Q)=2 \int_{0}^{1} d s(1-s) \exp \left[-\frac{Q^{2} a^{2} n}{6} s(1-s)\right]
$$

We notice the following identity:

$$
2 \int_{0}^{1} d s(1-s) \exp \left[-\frac{Q^{2} a^{2} n}{6} s(1-s)\right]=\int_{0}^{1} d s \exp \left[-\frac{Q^{2} a^{2} n}{6} s(1-s)\right] \text {. }
$$

Therefore:

$$
P(Q)=\int_{0}^{1} d s \exp \left[-\frac{Q^{2} a^{2} n}{6} s(1-s)\right]
$$

After integration variable changes and a few manipulations, one obtains the final result [17]:

$$
P(Q)=\frac{D(U)}{U}
$$

Here $\mathrm{D}(\mathrm{U})$ is Dawson's integral:

$$
\mathrm{D}(\mathrm{U})=\exp \left(-\mathrm{U}^{2}\right) \int_{0}^{\mathrm{U}} \mathrm{dt} \exp \left(\mathrm{t}^{2}\right)
$$


The variable $\mathrm{U}$ is given by $\mathrm{U}=\sqrt{\mathrm{Q}^{2} \mathrm{a}^{2} \mathrm{n} / 6} / 2=\mathrm{QR}_{\mathrm{g}} / 2$. Here $\mathrm{R}_{\mathrm{g}}=\mathrm{a} \sqrt{\mathrm{n} / 6}$ is the radius of gyration of the linear block of length $n$.

The method described here for a single ring can be generalized to calculate more complex structures containing looping features.

\subsection{Star Polymer with Looping Branches}

Consider a star polymer with looping branches as shown in Fig. 8. Each branch has $\mathrm{n}$ monomers of segment length a and there are $\mathrm{n}_{\mathrm{b}}$ branches. In order to use the multivariate Gaussian approach, the star with looping branches is opened up into a linear flexible chain of length $n_{b} n$.
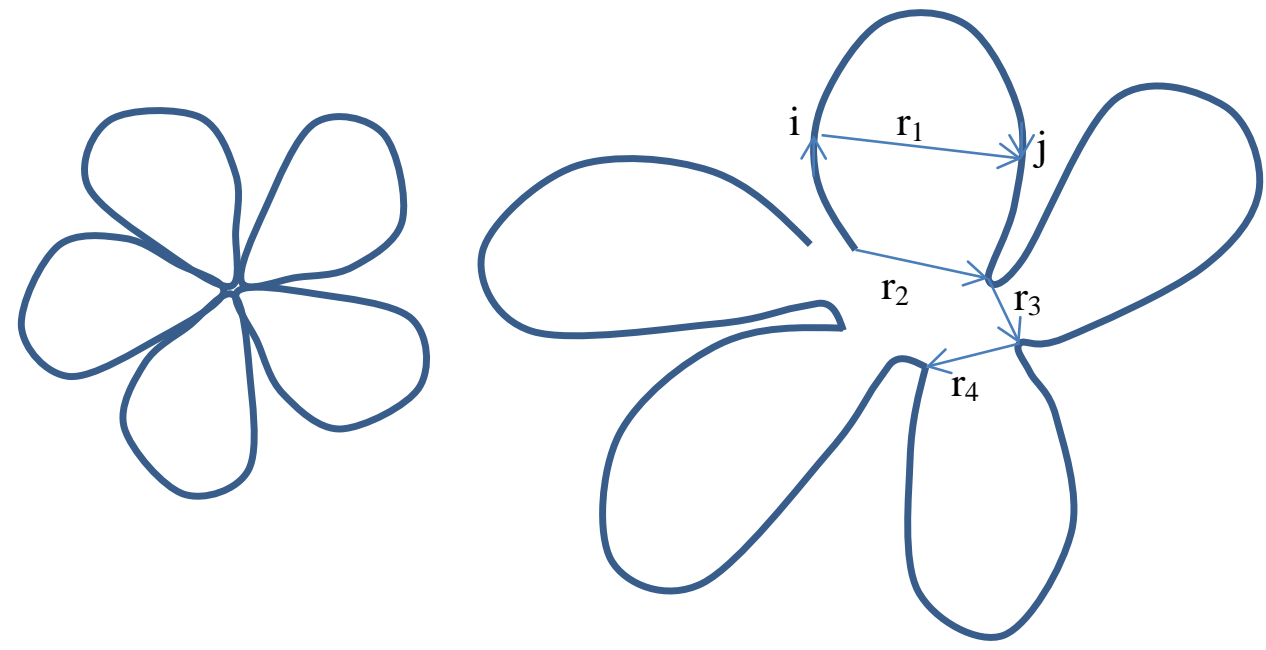

Fig. 8. The star with looping branches is opened up. The single-branch form factor involves monomer pairs $i$ and $j$ that belong to the same branch.

The correlation matrix for each loop is calculated as in the case of an isolated ring.

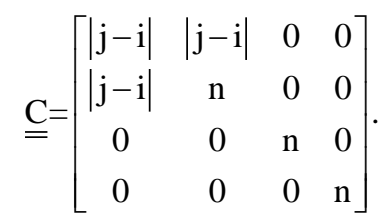

The determinant is:

$$
\Delta=n^{2}\left|\begin{array}{cc}
j-i & \mid j-i \\
|j-i| & n
\end{array}\right|=n^{2}(|j-i|)(n-|i-j|)
$$

The relevant (11) element of the inverse of the correlation matrix is:

$$
\mathrm{D}_{11}=\frac{\Delta_{11}}{\Delta}=\frac{\mathrm{n}^{3}}{\Delta}=\frac{\mathrm{n}}{(|\mathrm{j}-\mathrm{i}|)(\mathrm{n}-|\mathrm{i}-\mathrm{j}|)} .
$$

The single-branch form factor is: 


$$
\mathrm{P}_{\mathrm{sb}}(\mathrm{Q})=\frac{1}{\mathrm{n}^{2}} \sum_{\mathrm{i}, \mathrm{j}}^{\mathrm{n}} \exp \left[-\frac{\mathrm{Q}^{2} \mathrm{a}^{2}|\mathrm{i}-\mathrm{j}|}{6}\left(1-\frac{|\mathrm{i}-\mathrm{j}|}{\mathrm{n}}\right)\right] .
$$

The single-branch form factor amplitude is:

$$
\mathrm{F}_{\mathrm{sb}}(\mathrm{Q})=\frac{1}{\mathrm{n}} \sum_{\mathrm{i}}^{\mathrm{n}} \exp \left[-\frac{\mathrm{Q}^{2} \mathrm{a}^{2} \mathrm{i}}{6}\left(1-\frac{\mathrm{i}}{\mathrm{n}}\right)\right]
$$

Note that for polymer structures in general, the form factor (for monomers along the same chain portion) is not the square of the form factor amplitude. This is true only for particles with uniform density, not for polymers. For example, the so-called Debye function cannot be put in the form of a square. One can either proceed as described in the previous section to obtain an analytical result (in terms of the Dawson function) or perform the summations numerically.

In order to calculate the inter-branch form factor, monomers $\mathrm{i}$ and $\mathrm{j}$ belong to two different branches (Fig. 9).

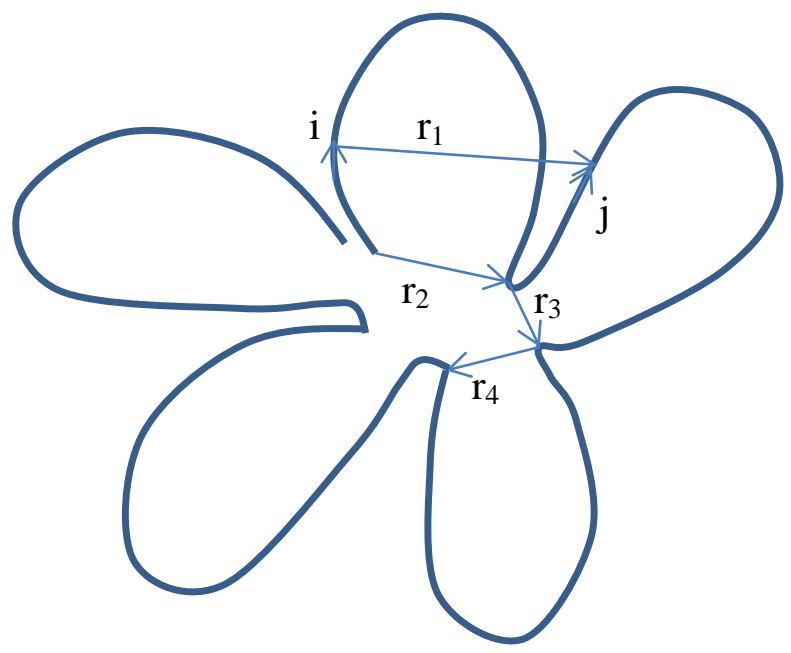

Fig. 9. The inter-branch form factor involves monomer pairs that belong to different branches.

The correlation matrix is:

$$
\stackrel{\mathrm{C}}{=}=\left[\begin{array}{cccc}
\mathrm{n}+\mathrm{j}-\mathrm{i} & \mathrm{n}-\mathrm{i} & \mathrm{j} & 0 \\
\mathrm{n}-\mathrm{i} & \mathrm{n} & 0 & 0 \\
\mathrm{j} & 0 & \mathrm{n} & 0 \\
0 & 0 & 0 & \mathrm{n}
\end{array}\right] .
$$

The determinant and the relevant element of the inverse matrix are given by: 


$$
\begin{aligned}
& \Delta=n^{2}\left[-i^{2}+i n+j(-j+n)\right] \\
& D_{11}=\frac{\left|\begin{array}{lll}
n & 0 & 0 \\
0 & n & 0 \\
0 & 0 & n
\end{array}\right|}{\Delta}=\frac{n^{3}}{\Delta}=\frac{n}{-i^{2}+i n+j(-j+n)} .
\end{aligned}
$$

For the sake of completeness, the pair of monomers are taken to belong to two non-adjacent looped branches (Fig. 10).

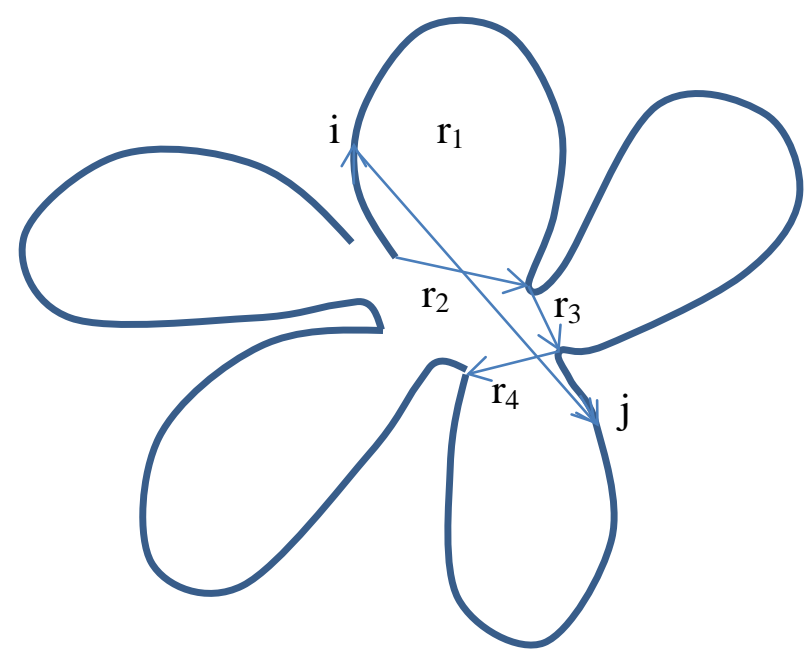

Fig. 10. The two correlated monomers belong to non-adjacent branches.

The result for $\mathrm{D}_{11}$ is identical to the previous result for adjacent branches. This conclusion was verified for branches that are separated by a couple of branches. This is expected since the opening up of the star with looping branches was arbitrary.

The single-branch and inter-branch form factors are expressed as:

$$
\begin{aligned}
& P_{s b}(Q)=\frac{1}{n^{2}} \sum_{i, j}^{n} \exp \left[-\frac{Q^{2} a^{2}|i-j|}{6}\left(1-\frac{|i-j|}{n}\right)\right] \\
& P_{i b}(Q)=\frac{1}{n^{2}} \sum_{i, j}^{n} \exp \left[-\frac{Q^{2}<r_{i j}^{2}>}{6}\right]=\frac{1}{n^{2}} \sum_{i, j}^{n} \exp \left[-\frac{Q^{2} a^{2}}{6 D_{11}}\right] \\
& P_{i b}(Q)=\frac{1}{n^{2}} \sum_{i, j}^{n} \exp \left[-\frac{Q^{2} a^{2}\left[-i^{2}+i n+j(-j+n)\right]}{6 n}\right] .
\end{aligned}
$$

The inter-branch form factor can be expressed as the product:

$$
\begin{aligned}
& P_{i b}(Q)=\frac{1}{n} \sum_{i}^{n} \exp \left[-\frac{Q^{2} a^{2} i(n-i)}{6 n}\right] \frac{1}{n} \sum_{j}^{n} \exp \left[-\frac{Q^{2} a^{2} j(n-j)}{6 n}\right] \\
& P_{i b}(Q)=|F(Q)|^{2} .
\end{aligned}
$$


In terms of the form factor amplitude for this inter-branch case:

$$
F(Q)=\frac{1}{n} \sum_{i}^{n} \exp \left[-\frac{Q^{2} a^{2} i(n-i)}{6 n}\right]
$$

which in the continuous limit can be expressed as:

$$
F(Q)=\int_{0}^{1} d s \exp \left[-\frac{Q^{2} a^{2} n}{6} s(1-s)\right] .
$$

This result can also be expressed in terms of the Dawson integral as follows:

$$
F(Q)=\frac{D(U)}{U}
$$

As before $U=\sqrt{Q^{2} a^{2} n / 6} / 2$. The total form factor for the star is formed using these results.

$$
\begin{aligned}
& \mathrm{P}_{\text {star }}(\mathrm{Q})=\frac{1}{\mathrm{n}_{\mathrm{b}}{ }^{2}}\left[\mathrm{n}_{\mathrm{b}} \mathrm{P}_{\mathrm{sb}}(\mathrm{Q})+\mathrm{n}_{\mathrm{b}}\left(\mathrm{n}_{\mathrm{b}}-1\right) \mathrm{P}_{\mathrm{ib}}(\mathrm{Q})\right] \\
& \mathrm{P}_{\text {star }}(\mathrm{Q})=\frac{1}{\mathrm{n}_{\mathrm{b}}{ }^{2}}\left[\mathrm{n}_{\mathrm{b}} \frac{\mathrm{D}(\mathrm{U})}{\mathrm{U}}+\mathrm{n}_{\mathrm{b}}\left(\mathrm{n}_{\mathrm{b}}-1\right)\left(\frac{\mathrm{D}(\mathrm{U})}{\mathrm{U}}\right)^{2}\right] .
\end{aligned}
$$

Note that these 2 approaches (analytical and numerical) have been verified to agree completely. The summations are performed numerically using the Mathematica software to plot the various form factors.

All these results are for Gaussian flexible polymer branches with no excluded volume. The singlebranch form factor $\mathrm{P}_{\mathrm{sb}}$, inter-branch form factor $\mathrm{P}_{\mathrm{ib}}$ and total star form factor $\mathrm{P}_{\text {star }}$ are plotted for a set of parameters $\left(\mathrm{n}_{\mathrm{b}}=3, \mathrm{a}=5 \AA\right.$, and $\left.\mathrm{n}=100\right)$ in Fig. 11. The star form factor varies between the single-branch and inter-branch ones as it should. The single-branch form factor has a dominant contribution compared to the inter-branch one. At low-Q, the inter-branch form factor dominates since this Q-window involves correlations between monomers separated by the size of a branch (at least).

Figure 12 shows Kratky plots for the same conditions. Since the high-Q limit follows $\mathrm{P}(\mathrm{Q} \rightarrow \infty)$ $1 / \mathrm{Q}^{2}$, the Kratky plot reaches a constant value asymptotically.

\subsection{Stars with Looping Branches and Excluded Volume}

The method of introducing excluded volume will be applied here to star-branched polymers with looping branches. Note that $v=0.5$ for Gaussian chains (no excluded volume) in theta conditions and $v=$ 0.6 (with full excluded volume) in good solvent conditions. The previous section corresponds to the case $v=0.5$.

The excluded volume parameter $v$ is introduced in the correlation matrix for the single-branch which becomes:

$$
\stackrel{\mathrm{C}}{=}=\left[\begin{array}{cccc}
|j-\mathrm{i}|^{2 v} & |\mathrm{j}-\mathrm{i}|^{2 v} & 0 & 0 \\
|\mathrm{j}-\mathrm{i}|^{2 v} & \mathrm{n}^{2 v} & 0 & 0 \\
0 & 0 & \mathrm{n}^{2 v} & 0 \\
0 & 0 & 0 & \mathrm{n}^{2 v}
\end{array}\right] .
$$




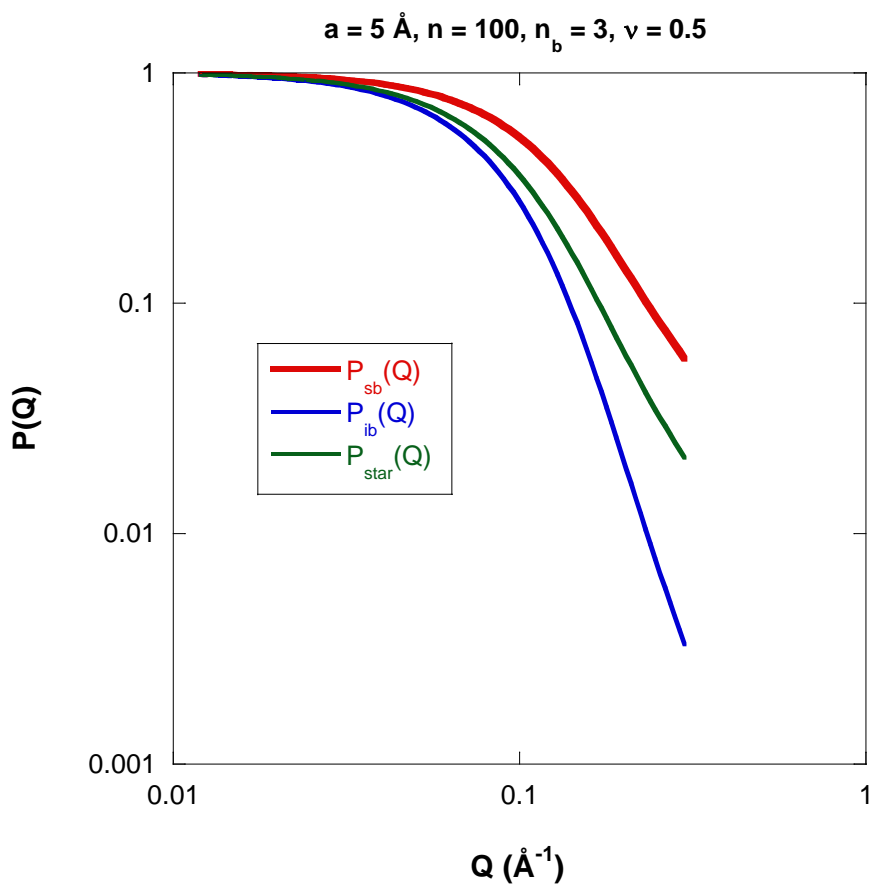

Fig. 11. Plot of the single-branch form factor $P_{s b}(Q)$, inter-branch form factor $P_{i b}(Q)$ and total star form factor $P_{\text {star }}(Q)$ for $n_{b}=3$, $\mathrm{a}=5 \AA$, and $\mathrm{n}=100$.

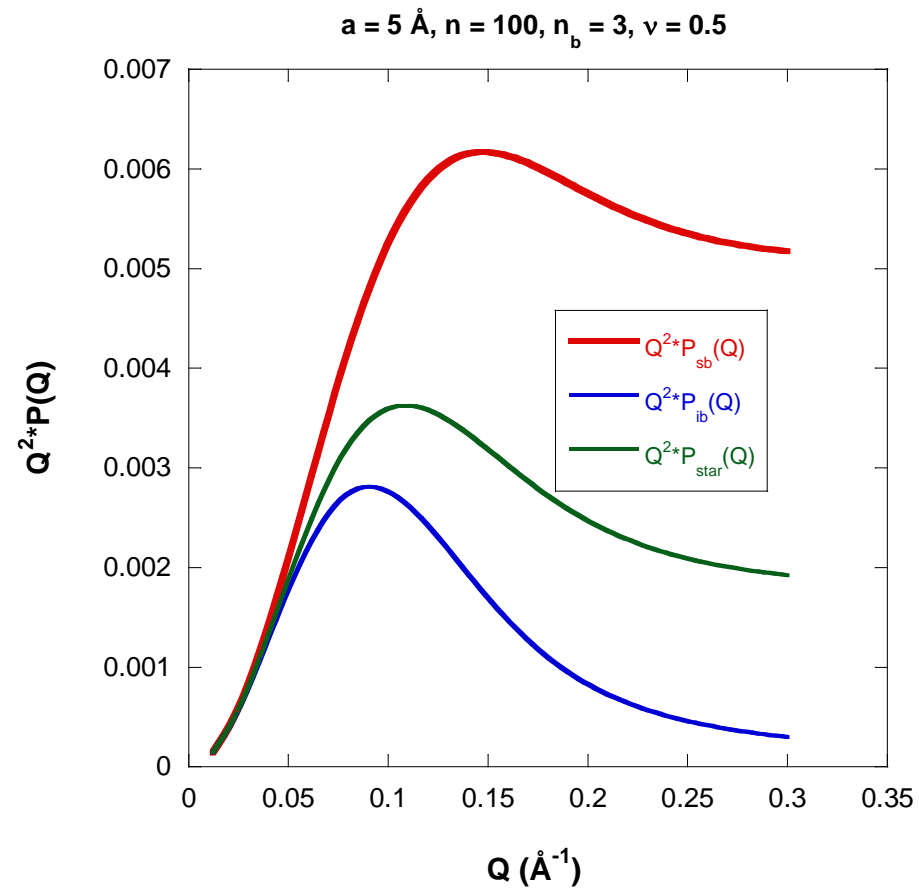

Fig. 12. Kratky Plot $\left(Q^{2} P(Q)\right.$ vs $\left.Q\right)$ for the single-branch form factor $P_{s b}(Q)$, inter-branch form factor $P_{i b}(Q)$ and total form factor $\mathrm{P}_{\text {star }}(\mathrm{Q})$ for $\mathrm{n}_{\mathrm{b}}=3$, $\mathrm{a}=5 \AA$, and $\mathrm{n}=100$. 
Similarly for the inter-branch, the correlation matrix becomes:

$$
\stackrel{\mathrm{C}}{=}=\left[\begin{array}{cccc}
|\mathrm{n}+\mathrm{j}-\mathrm{i}|^{2 v} & |\mathrm{n}-\mathrm{i}|^{2 v} & \mathrm{j}^{2 v} & 0 \\
|\mathrm{n}-\mathrm{i}|^{2 v} & \mathrm{n}^{2 v} & 0 & 0 \\
\mathrm{j}^{2 v} & 0 & \mathrm{n}^{2 v} & 0 \\
0 & 0 & 0 & \mathrm{n}^{2 v}
\end{array}\right] .
$$

As before, $\underline{\underline{D}}$ is calculated as the inverse of the correlation matrix $\left(\underline{\underline{D}}=\underline{\underline{C}}{ }^{-1}\right)$. All the various components are summarized here.

For the single-branch form factor with no excluded volume:

$$
\begin{aligned}
& \mathrm{D}_{11}=\frac{\Delta_{11}}{\Delta}=\frac{\mathrm{n}}{(|\mathrm{j}-\mathrm{i}|)(|\mathrm{n}-\mathrm{j}+\mathrm{i}|)} \\
& <\mathrm{r}_{\mathrm{ij}}^{2}>=\frac{\mathrm{a}^{2}}{\mathrm{D}_{11}}=\mathrm{a}^{2}|\mathrm{i}-\mathrm{j}|\left(1-\frac{|\mathrm{i}-\mathrm{j}|}{\mathrm{n}}\right) \\
& \mathrm{P}_{\mathrm{sb}}(\mathrm{Q})=\frac{1}{\mathrm{n}^{2}} \sum_{\mathrm{i}, \mathrm{j}}^{\mathrm{n}} \exp \left[-\frac{\mathrm{Q}^{2}<\mathrm{r}_{\mathrm{ij}}^{2}>}{6}\right]=\frac{1}{\mathrm{n}^{2}} \sum_{\mathrm{i}, \mathrm{j}}^{\mathrm{n}} \exp \left[-\frac{\mathrm{Q}^{2} \mathrm{a}^{2}}{6 \mathrm{D}_{11}}\right] .
\end{aligned}
$$

For the single-branch form factor with excluded volume:

$$
\begin{aligned}
& \mathrm{D}_{11}=\frac{\Delta_{11}}{\Delta}=\frac{(|-\mathrm{i}+\mathrm{j}|)^{-2 v} \mathrm{n}^{2 v}}{-(|-\mathrm{i}+\mathrm{j}|)^{2 v}+\mathrm{n}^{2 v}} \\
& <\mathrm{r}_{\mathrm{ij}}^{2}>=\frac{\mathrm{a}^{2}}{\mathrm{D}_{11}} \\
& \mathrm{P}_{\mathrm{sb}}(\mathrm{Q})=\frac{1}{\mathrm{n}^{2}} \sum_{\mathrm{i}, \mathrm{j}}^{\mathrm{n}} \exp \left[-\frac{\mathrm{Q}^{2} \mathrm{a}^{2}}{6 \mathrm{D}_{11}}\right] .
\end{aligned}
$$

For the inter-branch form factor with no excluded volume:

$$
\begin{aligned}
& \mathrm{D}_{11}=\frac{\Delta_{11}}{\Delta}=\frac{\mathrm{n}}{-\mathrm{i}^{2}+\mathrm{i} \mathrm{n}+\mathrm{j}(-\mathrm{j}+\mathrm{n})} \\
& <\mathrm{r}_{\mathrm{ij}}^{2}>=\frac{\mathrm{a}^{2}}{\mathrm{D}_{11}} \\
& \mathrm{P}_{\mathrm{ib}}(\mathrm{Q})=\frac{1}{\mathrm{n}^{2}} \sum_{\mathrm{i}, \mathrm{j}}^{\mathrm{n}} \exp \left[-\frac{\mathrm{Q}^{2} \mathrm{a}^{2}}{6 \mathrm{D}_{11}}\right] .
\end{aligned}
$$

For the inter-branch form factor with excluded volume: 


$$
\begin{aligned}
& \mathrm{D}_{11}=\frac{\Delta_{11}}{\Delta}=\frac{-\mathrm{n}^{2 v}}{\mathrm{j}^{4 v}+(-\mathrm{i}+\mathrm{n})^{4 v}-\mathrm{n}^{2 v}(-\mathrm{i}+\mathrm{j}+\mathrm{n})^{2 v}} \\
& <\mathrm{r}_{\mathrm{ij}}^{2}>=\frac{\mathrm{a}^{2}}{\mathrm{D}_{11}} \\
& \mathrm{P}_{\mathrm{ib}}(\mathrm{Q})=\frac{1}{\mathrm{n}^{2}} \sum_{\mathrm{i}, \mathrm{j}}^{\mathrm{n}} \exp \left[-\frac{\mathrm{Q}^{2} \mathrm{a}^{2}}{6 \mathrm{D}_{11}}\right] .
\end{aligned}
$$

For the inter-branch case, since the $\mathrm{i}$ and $\mathrm{j}$ indices are taken over different looping branches, all terms are positive and there is no need for the absolute value $(||)$.

The star polymer form factor (without or with excluded volume) combines these components:

$$
\mathrm{P}_{\text {star }}(\mathrm{Q})=\frac{1}{\mathrm{n}_{\mathrm{b}}^{2}}\left[\mathrm{n}_{\mathrm{b}} \mathrm{P}_{\mathrm{sb}}(\mathrm{Q})+\mathrm{n}_{\mathrm{b}}\left(\mathrm{n}_{\mathrm{b}}-1\right) \mathrm{P}_{\mathrm{ib}}(\mathrm{Q})\right]
$$

The various summations are performed numerically.

Overall the high-Q variation of the single-branch form factor (for the Kratky plot) keeps on increasing since it is dominant while that for the inter-branch decreases (Fig. 13).

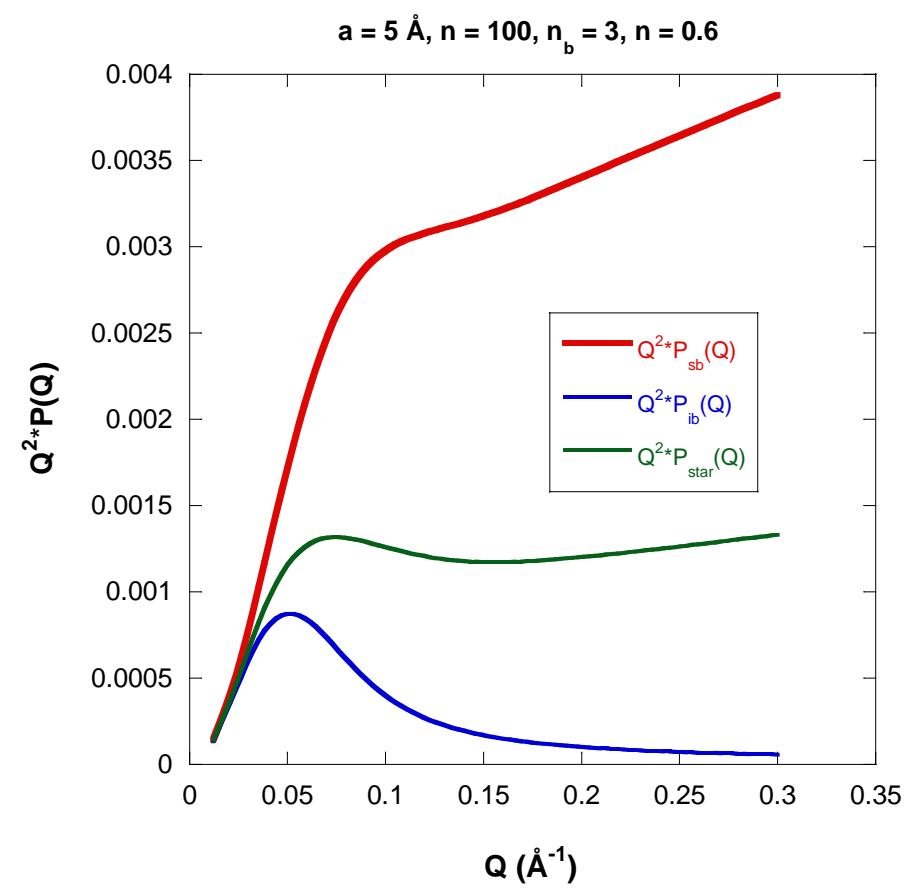

Fig. 13. Kratky Plot $\left(\mathrm{Q}^{2} \mathrm{P}(\mathrm{Q})\right.$ vs $\left.\mathrm{Q}\right)$ for the single-branch form factor $\mathrm{P}_{\mathrm{sb}}(\mathrm{Q})$, inter-branch form factor $\mathrm{P}_{\mathrm{ib}}(\mathrm{Q})$ and total form factor $\mathrm{P}_{\text {star }}(\mathrm{Q})$ for $\mathrm{n}_{\mathrm{b}}=3, \mathrm{a}=5 \AA$, and $\mathrm{n}=100$ with full excluded volume $(v=0.6)$. 
Figure 14 shows that the form factor with excluded volume $(v=0.6)$ keeps on increasing while that without excluded volume $(v=0.5)$ decreases at high-Q. This is due to the single-branch asymptotic variation which dominates. Note that $\mathrm{Q}^{2} \mathrm{P}_{\mathrm{sb}}(\mathrm{Q} \rightarrow \infty) \sim \mathrm{Q}^{2} 1 / \mathrm{Q}^{1 / v}$ so that $2-1 / v>0$ for $v=0.6$ but $2-1 / v=0$ for $v=0.5$.

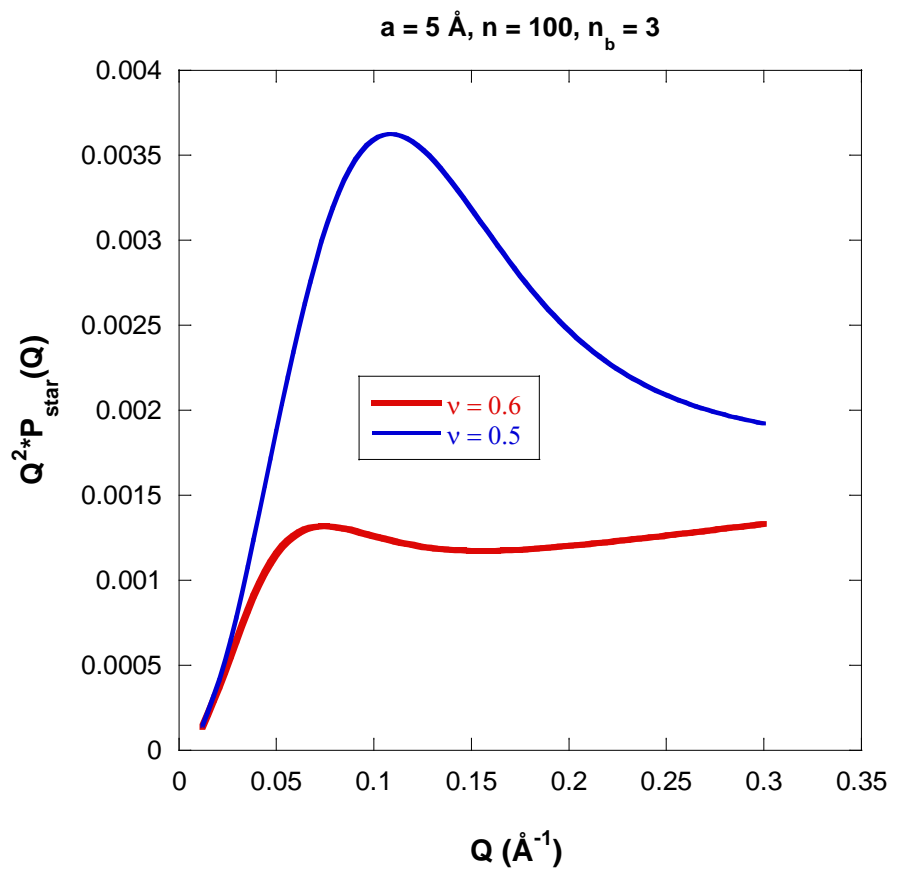

Fig. 14. Kratky Plot $\left(Q^{2} P(Q) v s \mathrm{Q}\right)$ for the star form factors $\mathrm{P}_{\text {star }}(\mathrm{Q})$ without $(v=0.5)$ and with $(v=0.6)$ excluded volume for $\mathrm{n}_{\mathrm{b}}=3$, $\mathrm{a}=5 \AA$, and $\mathrm{n}=100$.

\subsection{Polymer Ring with Excluded Volume}

When excluded volume is present, the form factor for ring polymers is similar to the single-branch form factor for stars with looping branches.

$$
\mathrm{P}_{\text {ring }}(\mathrm{Q})=\frac{1}{\mathrm{n}^{2}} \sum_{\mathrm{i}, \mathrm{j}}^{\mathrm{n}} \exp \left[-\frac{\mathrm{Q}^{2} \mathrm{a}^{2}}{6 \mathrm{D}_{11}}\right]
$$

where:

$$
\mathrm{D}_{11}=\frac{\Delta_{11}}{\Delta}=\frac{(|-\mathrm{i}+\mathrm{j}|)^{-2 v} \mathrm{n}^{2 v}}{-(|-\mathrm{i}+\mathrm{j}|)^{2 v}+\mathrm{n}^{2 v}}
$$

This form factor is simplified as follows:

$$
\begin{aligned}
& P_{\text {ring }}(Q)=\frac{1}{n^{2}} \sum_{i, j}^{n} \exp \left[-\frac{Q^{2} a^{2}|i-j|^{2 v}}{6}\left(1-\frac{|i-j|^{2 v}}{n^{2 v}}\right)\right] \\
& =\frac{1}{n^{2}}\left\{n+2 n \sum_{k=1}^{n}\left(1-\frac{k}{n}\right) \exp \left[-\frac{Q^{2} a^{2} k^{2 v}}{6}\left(1-\frac{k^{2 v}}{n^{2 v}}\right)\right]\right\} .
\end{aligned}
$$


The first term is dropped for $n>>1$. In order to simplify this equation, we take the continuous chain limit (whereby $Q^{2} a^{2} / 6<<1$ and $n>>1$ but keeping $Q^{2} a^{2} n^{2 v} / 6$ finite) and change the summations into integrations:

$$
\mathrm{P}_{\text {ring }}(\mathrm{Q})=2 \int_{0}^{1} \mathrm{ds}(1-\mathrm{s}) \exp \left[-\frac{\mathrm{Q}^{2} \mathrm{a}^{2} \mathrm{n}^{2 v}}{6} \mathrm{~s}^{2 v}\left(1-\mathrm{s}^{2 v}\right)\right] \text {. }
$$

This integral is doable analytically only for $v=1 / 2$ yielding the result in terms of the Dawson integral noted earlier.

The radius of gyration squared is given by:

$$
\mathrm{R}_{\mathrm{g}}{ }^{2}=\frac{1}{2} \sum_{\mathrm{i}, \mathrm{j}}^{\mathrm{n}} \mathrm{a}^{2}|\mathrm{i}-\mathrm{j}|^{2 v}\left(1-\frac{|\mathrm{i}-\mathrm{j}|^{2 v}}{\mathrm{n}^{2 v}}\right)
$$

or in an integral form after variable change:

$$
\begin{aligned}
& \mathrm{R}_{\mathrm{g}}{ }^{2}=\int_{0}^{1} \mathrm{ds}(1-\mathrm{s}) \mathrm{a}^{2} \mathrm{n}^{2 v} \mathrm{~s}^{2 v}\left(1-\mathrm{s}^{2 v}\right)=\mathrm{a}^{2} \mathrm{n}^{2 v}\left[\frac{1}{(2 v+1)(2 v+2)}-\frac{1}{(4 v+1)(4 v+2)}\right] \\
& \mathrm{R}_{\mathrm{g}}{ }^{2}=\frac{\mathrm{a}^{2} \mathrm{n}^{2 v}}{2}\left[\frac{3 v}{1+7 v+14 v^{2}+8 v^{3}}\right] .
\end{aligned}
$$

For $v=1 / 2$, the familiar result is recovered $R_{\mathrm{g}}{ }^{2}=\mathrm{a}^{2} \mathrm{n} / 12$ which is half the result for linear chains.

\subsection{Comparing Stars with Linear and Looping Branches}

The form factors for star-branched polymers with linear branches and with looping branches with and without excluded volume are compared in Fig. 15. Stars with looping branches appear more branched than the ones with linear branches. The case without excluded volume levels off at high-Q while the case with excluded volume keep on increasing as it should.

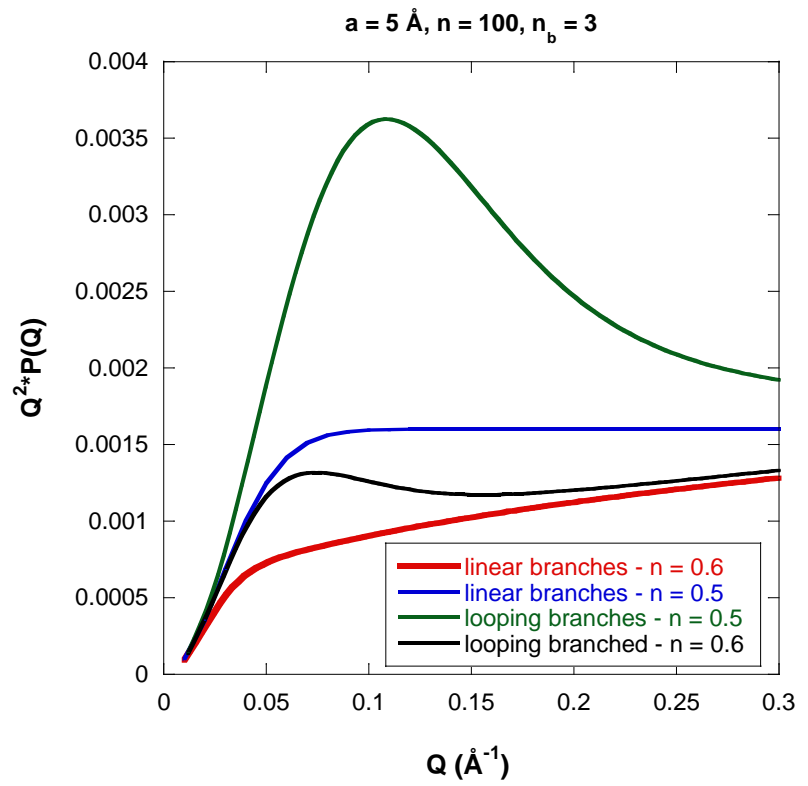

Fig. 15. Comparison of the two cases of stars with linear and with looping branches without and with excluded volume in each case and $\mathrm{n}_{\mathrm{b}}=3, \mathrm{a}=5 \AA$, and $\mathrm{n}=100$. 


\section{Form Factor for Dendrimers with Excluded Volume}

Dendrimers are highly branched polymers that build up a large number of blocks after a few generations (Fig. 16). This is due to the fact that the number of blocks gets multiplied by a multiplication factor $f$ at each generation. The form factor for flexible dendrimers has been calculated for Gaussian chain statistics [18].

This form factor is generalized here to incorporate chain swelling effect (chain excluded volume). As done in the previous sections, chain excluded volume is included following the Flory approach.

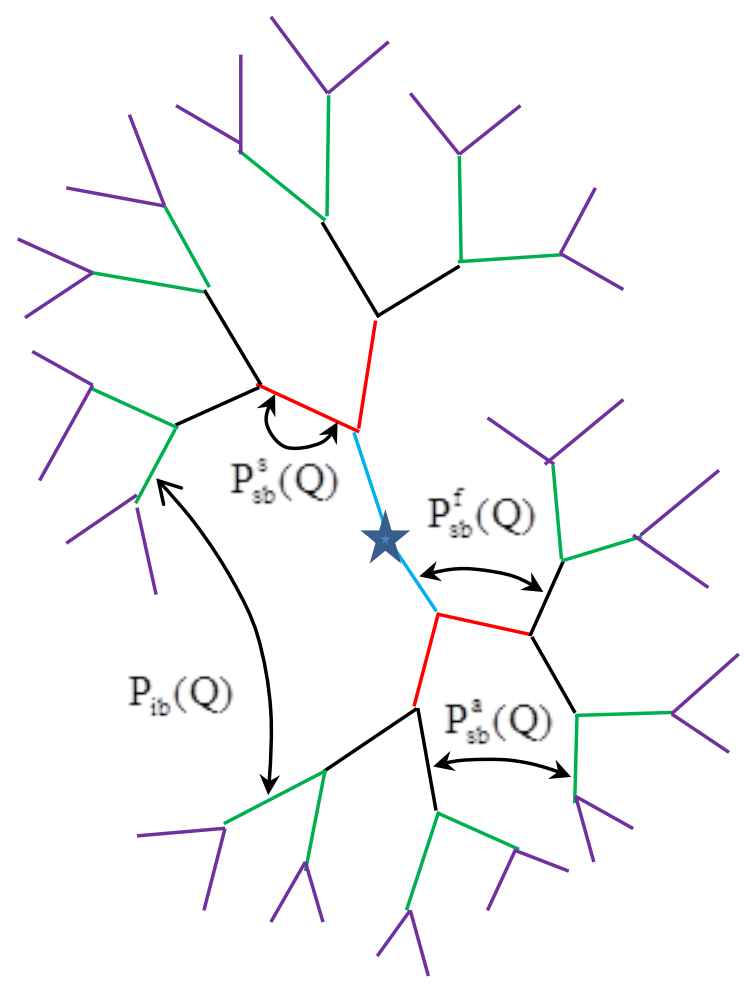

Fig. 16. Schematic representation of a dendrimer with $N_{g}=5$ (five generations), $n_{b}=2$ (two branches), and $f=2$ (number of blocks doubles at each generation).

\subsection{The Various Form Factors for Dendrimers}

Standard notation is used throughout. The number of generations is $\mathrm{N}_{\mathrm{g}}$, the number of branches is $\mathrm{n}_{\mathrm{b}}$ and $\mathrm{f}$ is the multiplication factor. Considering a pair of blocks, the main contributions to the form factor are included here. These are the single-branch "self" correlations $\mathrm{P}_{\mathrm{sb}}^{\mathrm{s}}(\mathrm{Q})$, the single-branch "forward" correlations $\mathrm{P}_{\mathrm{sb}}^{\mathrm{f}}(\mathrm{Q})$, the single-branch "across" correlations $\mathrm{P}_{\mathrm{sb}}^{\mathrm{a}}(\mathrm{Q})$, and the inter-branch correlations $\mathrm{P}_{\mathrm{ib}}(\mathrm{Q})$.

$$
\begin{aligned}
& P_{s b}^{s}(Q)=\frac{f^{N g}-1}{f-1} * P(\alpha) \\
& P_{s b}^{f}(Q)=2 \cdot \sum_{k=1}^{N g} f^{k-1} F(\alpha) \sum_{l=k+1}^{N g} f^{1-k} \cdot E(\alpha, 1-k-1) \cdot F(\alpha)
\end{aligned}
$$




$$
\begin{aligned}
& P_{s b}^{\mathrm{a}}(\mathrm{Q})=2 \cdot\left[\frac{\mathrm{f}(\mathrm{f}-1)}{2}\right] \cdot \sum_{\mathrm{r}=2}^{\mathrm{Ng}} \mathrm{f}^{\mathrm{r}-2} \sum_{\mathrm{k}=\mathrm{r}}^{\mathrm{Ng}} \mathrm{f}^{\mathrm{k}-\mathrm{r}} \mathrm{F}(\alpha) \sum_{\mathrm{l}=\mathrm{r}}^{\mathrm{Ng}} \mathrm{f}^{\mathrm{l}-\mathrm{r}} \cdot \mathrm{E}(\alpha, \mathrm{k}+1-2 * \mathrm{r}) \cdot \mathrm{F}(\alpha) \\
& \mathrm{P}_{\mathrm{ib}}(\mathrm{Q})=\sum_{\mathrm{k}=1}^{\mathrm{Ng}} \mathrm{f}^{\mathrm{k}-1} \mathrm{~F}(\alpha) \sum_{\mathrm{l}=1}^{\mathrm{Ng}} \mathrm{f}^{\mathrm{l}-1} \cdot \mathrm{E}(\alpha, \mathrm{k}+1-2) \cdot \mathrm{F}(\alpha) .
\end{aligned}
$$

Here $\alpha$ is related to the scattering variable $\mathrm{Q}$ and the statistical segment length a as $\alpha=\mathrm{Q}^{2} \mathrm{a}^{2} / 6$. Note that in these form factors expressions, summations over $\mathrm{k}$ and $\mathrm{l}$ are over blocks and that each block contains $\mathrm{n}$ monomers. It should be mentioned that the forms introduced here are complete and have been generalized to incorporate excluded volume. For instance, the present form for $\mathrm{P}_{\mathrm{sb}}^{\mathrm{a}}(\mathrm{Q})$ corrects the previous incomplete form [18].

Summations cover all block pairs to span the entire dendrimer. These partial form factors were obtained by starting from a small dendrimer (with a couple of generations only), then building up to the general case. These results have been verified to be correct by setting the $\alpha \rightarrow 0$ limit for which one can count the number of pairs directly from the dendrimer drawing.

The dendrimer form factor gathers all of these contributions as follows:

$$
P(Q)=\left(n_{b}\left[P_{s b}^{s}(Q)+P_{s b}^{f}(Q)+P_{a b}^{f}(Q)\right]+n_{b}\left(n_{b}-1\right) P_{i b}(Q)\right) / N_{T}^{2}
$$

where $\mathrm{N}_{\mathrm{T}}=\mathrm{n}_{\mathrm{b}} \frac{\left(\mathrm{f}^{\mathrm{Ng}}-1\right)}{(\mathrm{f}-1)}$ is the total number of blocks.

The various partial correlation factors have been defined according to the number of summations involved as shown in Fig. 17. $\mathrm{P}(\alpha)$ is the form factor, $F(\alpha)$ is the form factor amplitude and $E(\alpha)$ is the propagation factor.

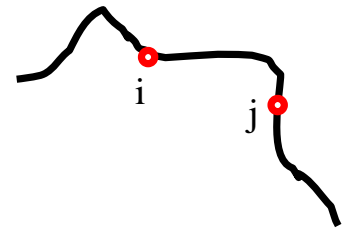

$\mathrm{P}(\alpha)$

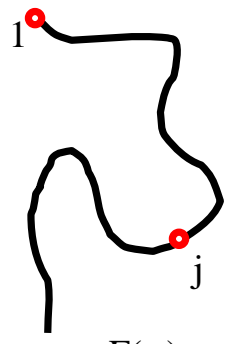

$\mathrm{F}(\alpha)$

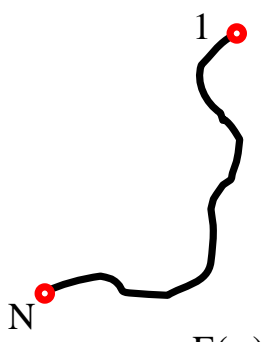

$\mathrm{E}(\alpha)$

Fig. 17. Notation representing the various correlation factors.

This allows us to form inter-block correlations following the simple rule shown in the following example (Fig. 18).
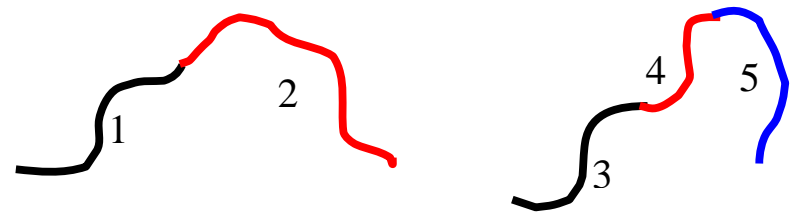

Fig. 18. Cases of a diblock and a triblock copolymers. 
In the two examples considered, the following cross correlations can be formed as: $P_{12}(Q)=F_{1}(\alpha) F_{2}(\alpha)$ and $\mathrm{P}_{35}(\mathrm{Q})=\mathrm{F}_{3}(\alpha) \mathrm{E}_{4}(\alpha) \mathrm{F}_{5}(\alpha)$.

The form factor for a polymer chain segment containing $n$ monomers with excluded volume is reproduced here for completeness $[13,14]$.

$$
\mathrm{P}(\mathrm{Q})=\frac{1}{v \mathrm{U}^{1 / 2 v}} \gamma\left(\frac{1}{2 v}, \mathrm{U}\right)-\frac{1}{v \mathrm{U}^{1 / v}} \gamma\left(\frac{1}{v}, \mathrm{U}\right) .
$$

Here, $\gamma(x, U)$ is the incomplete gamma function defined before. The variable $U$ is given in terms of the scattering variable $\mathrm{Q}$ as:

$$
\mathrm{U}=\frac{\mathrm{Q}^{2} \mathrm{a}^{2} \mathrm{n}^{2 v}}{6}=\alpha \mathrm{n}^{2 v}
$$

The form factor amplitude is also given in terms of the incomplete gamma function as:

$$
\mathrm{F}(\mathrm{Q})=\frac{1}{2 v \mathrm{U}^{\frac{1}{2 v}}} \gamma\left(\frac{1}{2 v}, \mathrm{U}\right)
$$

Finally, the propagation factor for an intermediate block with $\mathrm{m}^{*} \mathrm{n}$ monomers is given by:

$$
\mathrm{E}(\alpha, \mathrm{m})=\exp \left(-\alpha\left(\mathrm{m}^{*} \mathrm{n}\right)^{2 v}\right)
$$

The case for pure Gaussian chain statistics (i.e., with no excluded volume) is obtained for $v=0.5$. In this case, the various terms simplify as described here. For a block of $n$ monomers, the form factor, form factor amplitude and propagator become:

$$
\begin{aligned}
& P(\alpha n)=2 \frac{\exp (-\alpha n)-1+\alpha n}{(\alpha n)^{2}} \\
& F(\alpha n)=\frac{1-\exp (-\alpha n)}{(\alpha n)} \\
& E(\alpha, m)=\exp (-\alpha n \cdot m) .
\end{aligned}
$$

The propagator was taken over $m$ blocks of $n$ monomers each. This simplified form of $P(\alpha n)$ is the familiar Debye function.

\subsection{Form Factors Trends}

Here also, Mathematica was used to perform the various summations and plot a series of figures in order to document the trends. The limiting case with $\mathrm{f}=1$ was checked and found to agree with the star polymer with linear branches.

The dendrimer form factor $\mathrm{P}_{\text {dend }}(\mathrm{Q})$ is plotted for a realistic set of parameters both with $(v=0.6)$ and without $(v=0.5)$ excluded volume. $\mathrm{P}_{\text {dend }}(\mathrm{Q})$ is normalized to 1 at low-Q. At high-Q, the asymptotic limit $\mathrm{P}_{\text {dend }}(\mathrm{Q})$ obeys the asymptotic limit $\mathrm{Q}^{1 / v}$ as expected (Fig. 19).

The Kratky plot for dendrimers with $(v=0.6)$ and without $(v=0.5)$ excluded volume. $\left(\mathrm{Q}^{2} * \mathrm{P}_{\text {dend }}(\mathrm{Q})\right.$ vs $\left.\mathrm{Q}^{2}\right)$ presents a peak that represents the boundary between the single-branch and inter-branch contributions 
(Fig. 20). The case with excluded volume has a peak at lower Q since fully swollen chains are more extended that ideal ones.

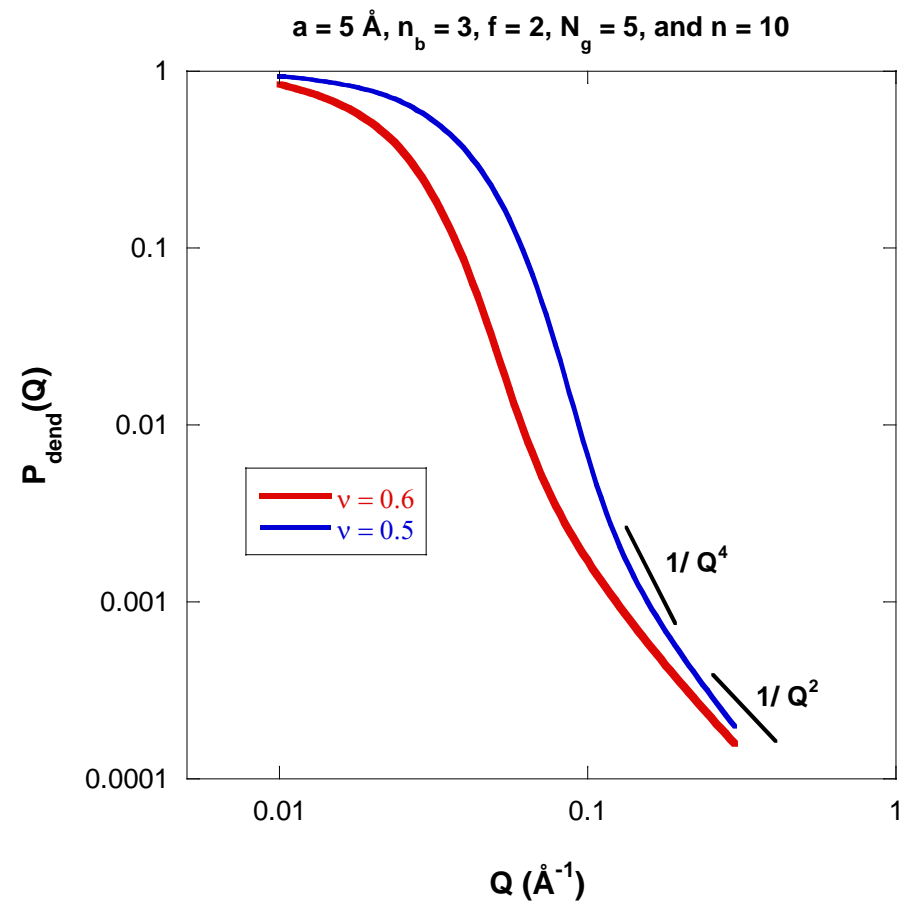

Fig. 19. Dendrimer form factor $P_{\text {dend }}(Q)$ for $a=5 \AA, n_{b}=3, f=2, N_{g}=5$, and $n=10$ without and with excluded volume.

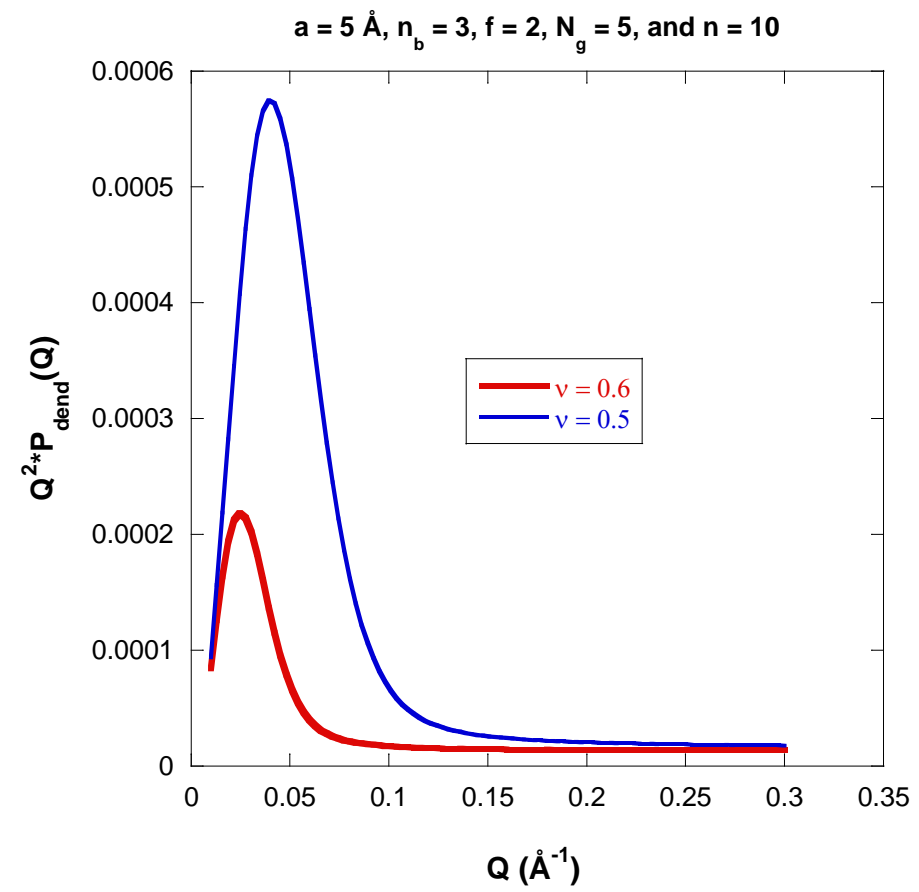

Fig. 20. Kratky plot for the same conditions as the previous figure. 
Figure 21 compares the effect of excluded volume for the various partial form factors. Chain swelling has the effect of shifting the form factors to lower-Q. Chain swelling has strong effect on the overall dendrimer structure (i.e., at low-Q) but has a smaller effect on the local dendrimer structure (at high-Q).

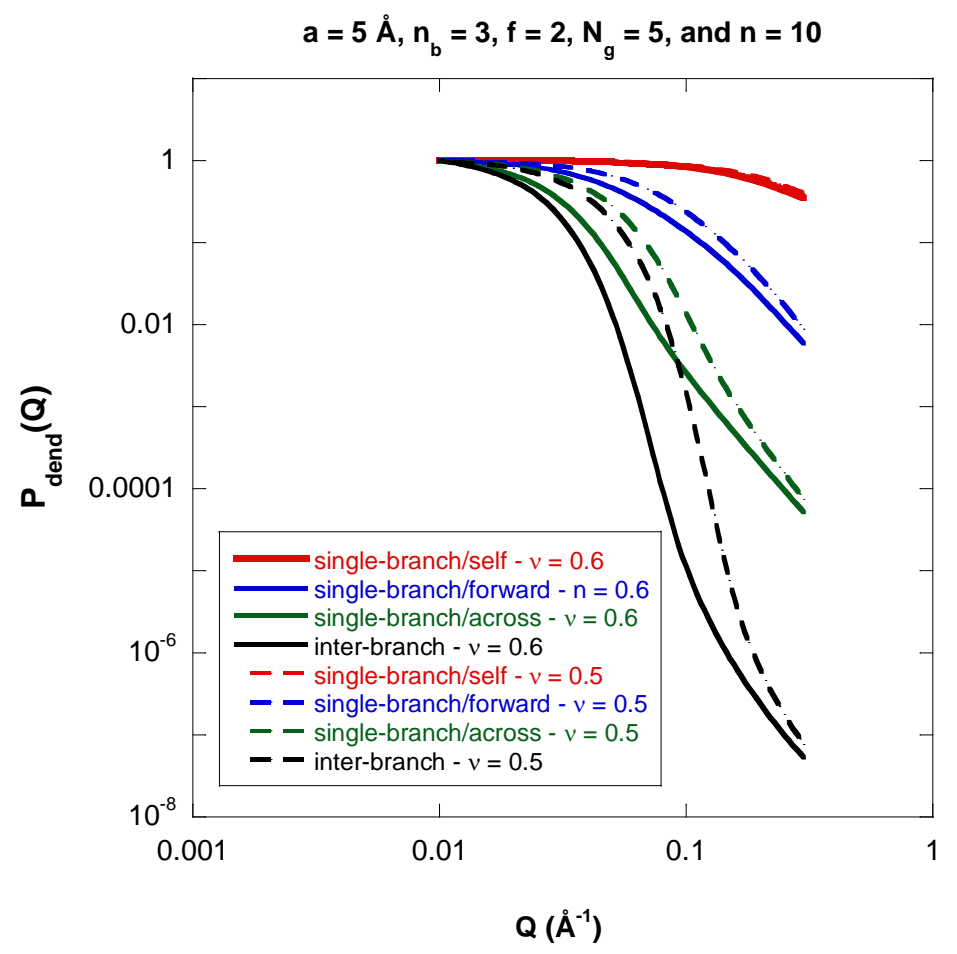

Fig. 21. Dendrimer partial form factors for $a=5 \AA, n_{b}=3, f=2, N_{g}=5$, and $n=10$ without and with excluded volume.

When the block multiplication factor $\mathrm{f}$ is increased, the Kratky plot shows increased branching as evidenced by a more pronounced peak (Fig. 22). The peak position moves towards lower-Q. The $\mathrm{f}=1$ case reproduces the linear star form factor, which does not have a peak in the Kratky plot for $n_{b}=3$.

When the number of dendrimer generations is increased, the dendrimers become larger but the overall shape of the form factor remains unchanged (Fig. 23). Note the high-Q asymptotic scaling behavior $1 / \mathrm{Q}^{5 / 3} \mathrm{P}_{\text {dend }}(\mathrm{Q}) \sim 1 / \mathrm{Q}^{1 / v} \sim 1 / \mathrm{Q}^{5 / 3}$ coming from the single-block form factor and the intermediate-Q scaling $1 / \mathrm{Q}^{10 / 3}$ which involves the square of the form factor amplitude $|\mathrm{F}(\mathrm{Q})|^{2} \sim 1 / \mathrm{Q}^{2 / v} \sim 1 / \mathrm{Q}^{10 / 3}$ in the fully swollen chain case $(v=3 / 5=0.6)$. 


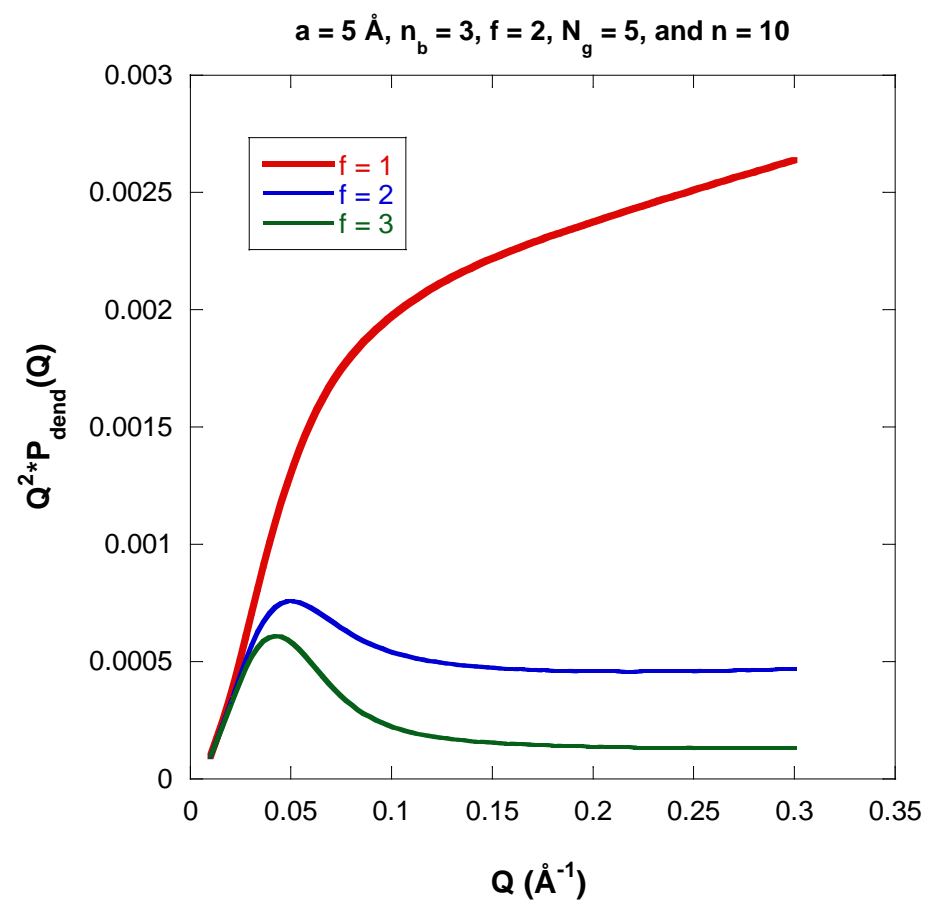

Fig. 22. Kratky plot for the same conditions as before with excluded volume $(v=0.6)$ but varying the generation multiplication factor $\mathrm{f}$.

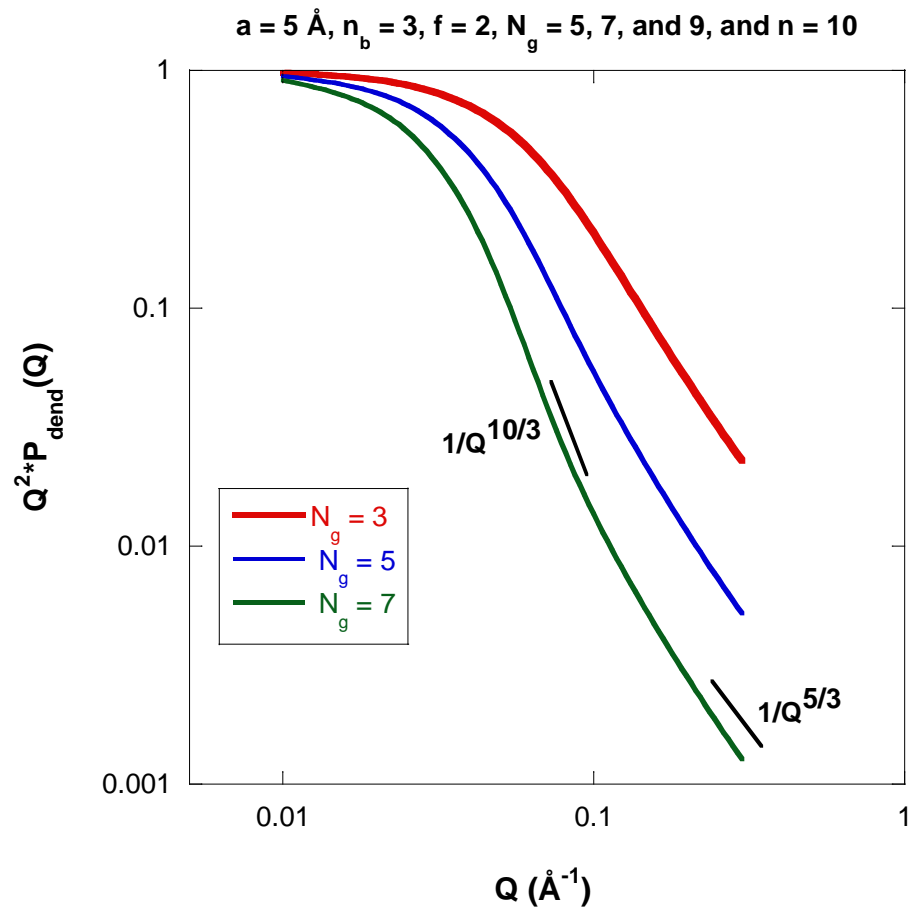

Fig. 23. Kratky plot for the same conditions as before with excluded volume $(v=0.6)$ but varying the number of generations $\mathrm{N}_{\mathrm{g}}$. 


\subsection{Comments}

The form factor for dendrimers presented here is complete and has been generalized to include chain swelling. Since this general form could not be simplified to an analytical form, it is kept in terms of numerical summations. The functional forms for the nonlinear least-squares fitting form factor would involve such summations.

There are two forms of excluded volume, one due to chain swelling discussed here and the other due to the physical exclusion of chain portions by other branches to avoid block overlap especially close the dendrimer center. This second form of excluded volume could not be accounted for by a Flory-type of approach. Such contribution could be accounted for only through computer simulation.

Results were presented in a compact form involving numerical summations. The various partial form factors were discussed in detail and trends of their behavior were documented.

\section{Summary}

The form factor for branched polymers with chain-swelling excluded volume was calculated for starbranched polymers and dendrimers. The approach presented here is simple enough to be tractable. It is based on the Flory idea of excluded volume, which was developed to obtain analytical expressions involving incomplete gamma functions. It has been extended to many cases of branched systems and yielded reasonable results. This form factor is dominated by the inter-chain contributions at low-Q and by the single-chain contributions at high-Q. The transition between these two regions is characterized by a peak in the Kratky plot. In the case of star-branched polymers with linear branches, the inter-branch form factor was expressed in two forms, one approximate form using form factor amplitudes and the other formally "exact" (within this formalism) using form factors and the binomial formula to calculate the cross terms.

In the case of star-branched polymers with looping branches, an original idea of building looped branches from linear chains then applying judicious "crosslinks" allowed the use of the multivariate Gaussian distribution to obtain compact results. The form factor for ring polymers with excluded volume was obtained from the single-branch scattering factor for stars with looping branches. The corresponding radius of gyration was included as well. In the case of dendrimers, the complete and general case that incorporates excluded volume is presented here for the first time. In fact, lots of the material presented in this paper is original and cannot be found in the open literature. It is felt that such form factors are much needed to analyze scattering data.

Note that the form factor alone is not enough to analyze scattering data. Structure factor contributions due to finite concentration effects should be included. This is outside of the scope of this theoretical contribution. The Random Phase Approximation (RPA) is a valuable method for expressing structure factors for polymer mixtures in solution as well as the blend state [13].

\section{Acknowledgements}

Informative discussions with Vivek Prabhu and Wei-Ren Chen are appreciated. This work is based upon activities supported in part by the National Science Foundation under Agreement No. DMR-1508249.

\section{References}

[1] Benoit H (1953) On the effect of branching and polydispersity on the angular distribution of the light scattered by Gaussian coils. J Polym Sci 11(5):507-510. http://dx.doi.org/10.1002/pol.1953.120110512

[2] Li X, Do C, Liu Y, Sánchez-Diáz L, Smith G, \& Chen W-R (2014) A scattering function of star polymers including excluded volume effects. J Appl Cryst 47(6):1901-1905. http://dx.doi.org/10.1107/S1600576714022249

[3] Eizenberg N \& Klafter J (1993) Self-avoiding walks on a simple cubic lattice. J Chem Phys 99(5):3976-3982. http://dx.doi.org/10.1063/1.466144 
[4] Valleau JP (1996) Distribution of end-to-end length of an excluded-volume chain. J Chem Phys 104(8):3071-3074. http://dx.doi.org/10.1063/1.471073

[5] des Cloizeaux J (1974) Lagrangian theory for a self-avoiding random chain. Physical Review A 10(5):1665-1669.

[6] Ohta T, Oono Y, \& Freed KF (1982) Static-coherent-scattering function for a single polymer-chain - conformational space renormalization of polymers. Physical Review A 25(5):2801-2811. http://dx.doi.org/10.1103/PhysRevA.25.2801

[7] Alessandrini JL \& Carignano MA (1992) Static scattering function for a regular star-branched polymer. Macromolecules 25(3):1157-1163. http://dx.doi.org/10.1021/Ma00029a024

[8] Boothroyd AT, Squires GL, Fetters LJ, Rennie AR, Horton JC, \& De Vallera AMBG (1989) Small-angle neutron scattering from star-branched polymers in dilute solution. Macromolecules 22(7):3130-3137. http://dx.doi.org/10.1021/ma00197a040

[9] Horton JC, Squires GL, Boothroyd AT, Fetters LJ, Rennie AR, Glinka CJ, \& Robinson RA (1989) Small-angle neutron scattering from star-branched polymers in the molten state. Macromolecules 22(2):681-686. http://dx.doi.org/10.1021/ma00192a029

[10] Borisov OV, Zhulina EB, Leermakers FAM, \& Muller AHE (2011) Self-assembled structures of amphiphilic ionic block copolymers: theory, self-consistent field modeling and experiment. Adv Polym Sci 241:57-129. http://dx.doi.org/10.1007/12_2011_114

[11] Dozier WD, Huang JS, \& Fetters LJ (1991) Colloidal nature of star polymer dilute and semidilute solutions. Macromolecules 24(10):2810-2814. http://dx.doi.org/10.1021/Ma00010a026

[12] Akcasu AZ \& Benmouna M (1978) Concentration effects on the dynamic structure factor in polymer solutions. Macromolecules 11(6):1193-1198. http://dx.doi.org/10.1021/ma60066a024

[13] Hammouda B (1993) SANS from homogeneous polymer mixtures: A unified overview. Advances in Polym Sci 106:87-133. http://dx.doi.org/10.1007/BFb0025862

[14] Benoit H (1957) La diffusion de la lumiere par des macromolecules en chaines en solution dans un bon solvant. Cr Hebd Acad Sci 245(25):2244-2247.

[15] Fukatsu M \& Kurata M (1966) Hydrodynamic properties of flexible-ring macromolecules. J Chem Phys 44(12):4539-4545. http://dx.doi.org/10.1063/1.1726671

[16] Hammouda B (1993) Structure factors for regular polymer gels and networks. J Chem Phys 99(11):9182-9187. http://dx.doi.org/10.1063/1.465533

[17] Casassa EF (1965) Some statistical properties of flexible ring polymers. J Polym Sci Part A 3(2pa):605-614. http://dx.doi.org/10.1002/pol.1965.100030217

[18] Hammouda B (1992) Scattering factor for starburst dendrimers. J Polym Sci, Polym Phys Ed 30:1387-1390. http://dx.doi.org/10.1002/polb.1992.090301209

About the author: Boualem Hammouda is a senior scientist in the Center for Neutron Research at NIST. He has been carrying out research in the area of small-angle neutron scattering for over 25 years. Check out his publications at http://www.ncnr.nist.gov/staff/hammouda/. The National Institute of Standards and Technology is an agency of the U.S. Department of Commerce. 